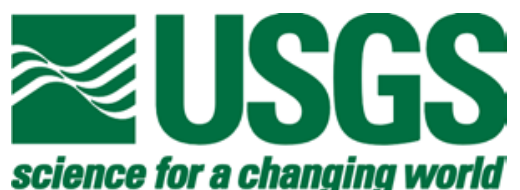

Prepared in cooperation with the U.S. Department of Energy, under

Interagency Agreement DE-AI07-92-ID13207, Modification A012

\title{
Final Report \\ VETEM (Very Early Time Electromagnetic) System \\ Survey of Pit 4 and Pit 10 Subsurface Disposal Area, Radioactive Waste Management Complex, Idaho National Engineering and Environmental Laboratory, Idaho Falls, ID
}

By Jared D. Abraham, David VonG. Smith, and David L. Wright

This report is preliminary and has not been reviewed for conformity with U.S. Geological Survey editorial standards or within the North American Stratigraphic Code.

Any use of trade, firm, or product names is for descriptive purposes only and does not imply endorsement by the U.S. Government.

Open-File Report 03-140

U.S Department of Interior

U.S. Geological Survey 


\section{Table of Contents}

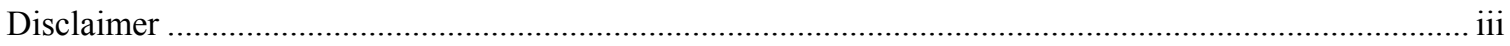

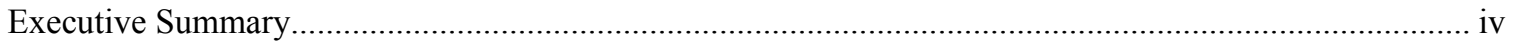

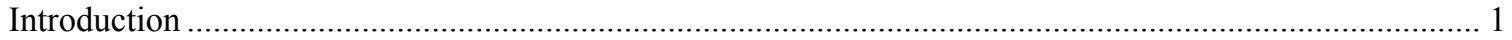

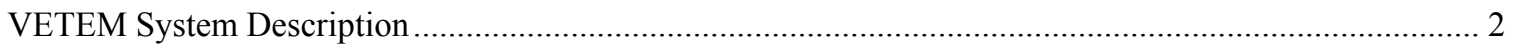

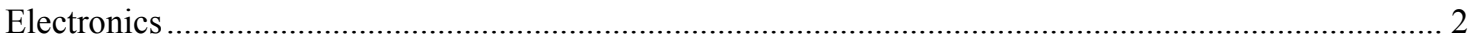

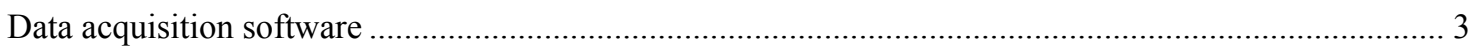

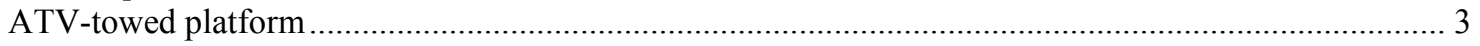

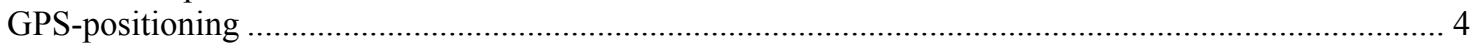

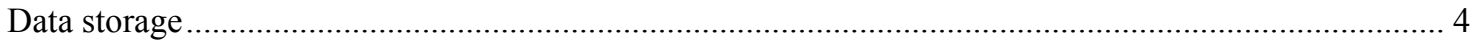

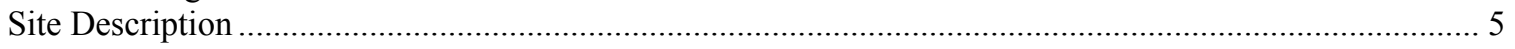

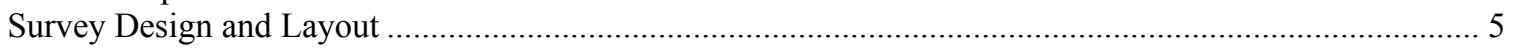

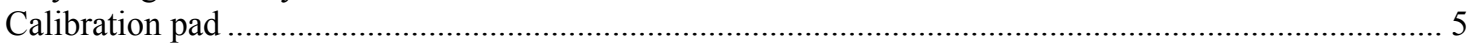

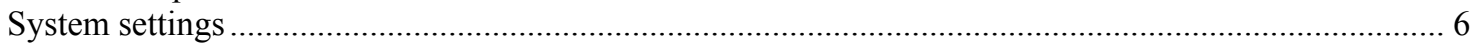

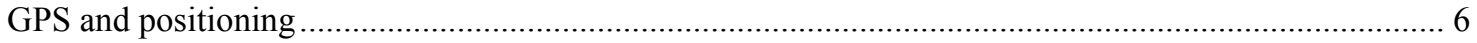

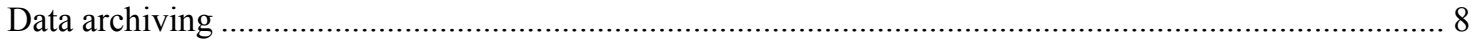

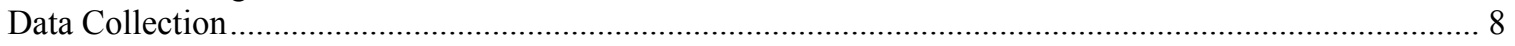

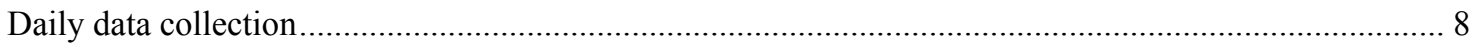

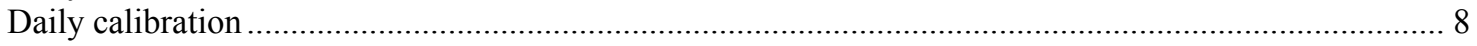

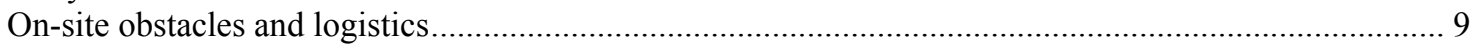

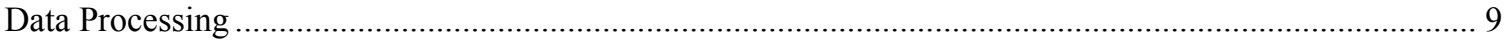

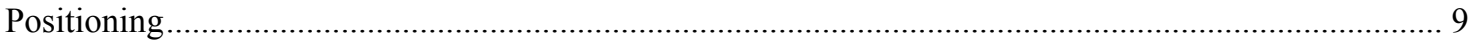

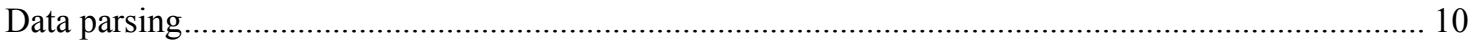

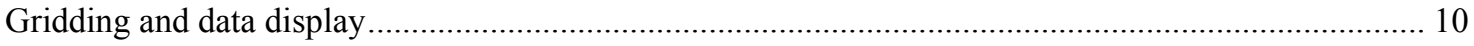

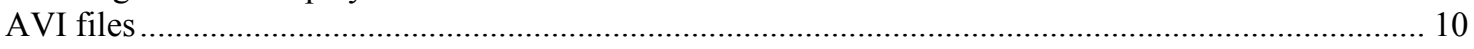

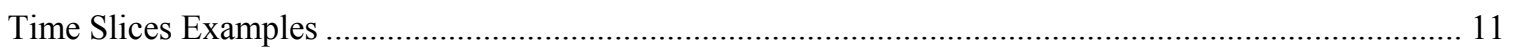

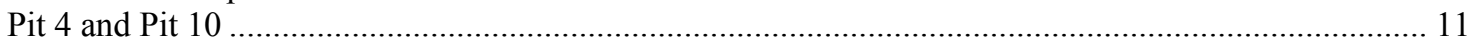

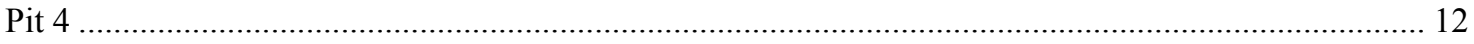

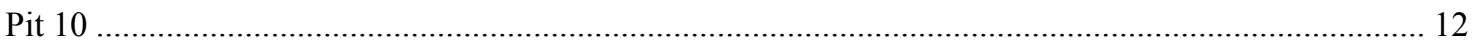

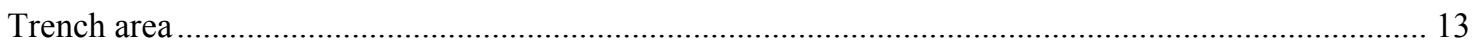

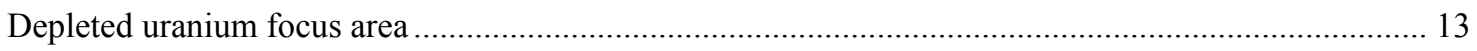

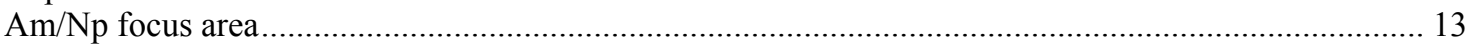

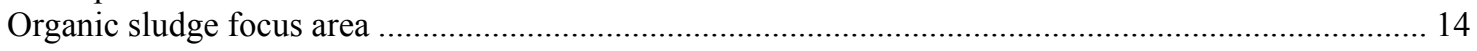

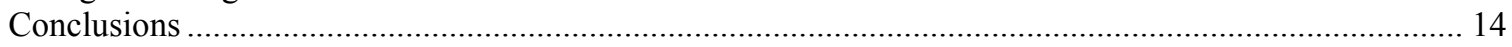

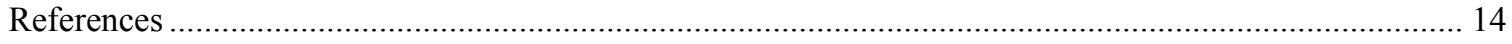

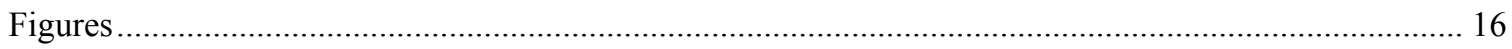




\section{Disclaimer}

This open-file report was prepared by an agency of the United States Government. Neither the United States Government nor any agency thereof nor any of their employees makes any warranty, expressed or implied, or assumes any legal liability or responsibility for the accuracy, completeness, or usefulness of any information, apparatus, product, or process disclosed in this report or represents that its use would not infringe privately owned rights. Reference therein to any specific commercial product, process, or service by trade name, trademark, manufacturer, or otherwise does not constitute or imply its endorsement, recommendation, or favoring by the United States Government or any agency thereof.

Although all data and software in this open-file report have been used by the USGS, no warranty, expressed or implied, is made by the USGS as to the accuracy of the data and related materials and (or) the functioning of the software. The act of distribution shall not constitute any such warranty, and no responsibility is assumed by the USGS in the use of these data, software, or related materials. 


\section{Executive Summary}

This final report meets the requirements of the Scope of Work of Interagency Agreement DE-AI07-92ID13207, Modification A012. . The objective of this report is to briefly describe the VETEM system, data collection procedures, and display the preliminary raw images of the data. Within this report images are presented from the deployment of the USGS prototype Very Early Time Electromagnetic (VETEM) system at Pits 4 and 10 within the Subsurface Disposal Area (SDA) of the Radioactive Waste Management Complex (RWMC) at the Idaho National Engineering and Environmental Laboratory (INEEL). These images are of raw data that have not been leveled nor has the system response been removed. The images are positioned with a real time kinematic global positioning system (RTK-GPS). The data have been processed for position accuracy and data validity. Images are produced from selected time slices of the VETEM data. Results indicate the VETEM system is responding throughout the recorded time series and can detect many subsurface conductive objects within Pit 4 and Pit 10. Digital images are contained within this report for the presented results. There are also AVI files showing the data at selected times throughout the recorded time series. Further details on the system can be found in the VETEM final report at

http://www.osti.gov/em52/final_reports/60162.pdf. 


\section{Introduction}

The images of Pits 4 and 10 in the Subsurface Disposal Area (SDA) of the Radioactive Waste Management Complex (RWMC) at the Idaho National Engineering and Environmental Laboratory (INEEL) contained in this report were produced from data recorded by the U.S. Geological Survey (USGS) prototype Very Early Time Electromagnetic (VETEM) system. The VETEM system is a prototype whose development was supported by the U.S. Department of Energy's Environmental Management Science Program (EMSP). VETEM can be configured in a number of ways for different applications, but the main aim for VETEM is to improve shallow subsurface electromagnetic imaging in environments where the electrical conductivity is too high for ground-penetrating radar (GPR) to be effective. Some of the specific goals of VETEM include:

- Better penetration than GPR through conductive soils,

- Better shallow resolution than conventional time-domain electromagnetic (TDEM) systems,

- Ability to map earth conductivities,

- Ability to distinguish between high conductivities of geologic origin, and buried metal objects,

- Response to both conductivity and dielectric properties where feasible, and

- Effective 2D and 3D visualizations of our results.

This report shows time-slice images that illustrate some of the time variations in our data. The VETEM system, as a research prototype, is constantly being improved to make it more effective for a wider range of shallow earth imaging problems of interest to the Department of Energy and to other agencies that have similar needs. Coverage of areas as large as Pits 4 and 10 would have been impractical without our very recent adaptation of the system to an all terrain vehicle (ATV)-towed system. This work is the first completed using the ATV-towed version of VETEM.

Projects funded by the EMSP must have both technical merit and relevance to the Environmental Management problems of concern to the DOE. We are delighted to have been afforded this opportunity to test and demonstrate the effectiveness and relevance of our VETEM work at INEEL. 


\section{VETEM System Description}

\section{Electronics}

For the work at INEEL, VETEM was configured with a horizontal transmitting loop and a vertical receiving loop. A ramped pulse is sent to the transmitting loop and an analog amplifier chain conditions the received signal from the receiving loop for the A/D (analog to digital) converter boards. The A/D boards then send the digitized signal to the computer for storage and display.

The physical configuration of the system consists of a towed trailer and an ATV. The trailer is made of fiberglass and other non-metallic materials and carries the antennas, transmitter, receiver, and a Global Positioning System (GPS) antenna. The transmitter and receiver have their own battery packs and are directly attached to the antennas. The transmitter (Tx) and receiver $(\mathrm{Rx})$ communicate to the data acquisition system on the ATV by fiber optics. Thus no long wires are near the antennas. There are three fiber optic channels. One fiber optic channel provides control of the transmitter turn-on and turn-off times. A second fiber optic channel provides setup control of the receiver. The remaining optical channel provides an analog signal path from the receiver. A coaxial cable provides contact with the GPS, which is located far enough away from the antennas to avoid interference.

The sequence of events and timing are as follows. Setup signals are sent to: the receiver, the A/D boards, and the delay module. These control signals determine: the antenna orientation, the receiver gain, the low pass filter cutoff, the number of sample points, and the number of stacks (averages).

As shown in the VETEM block diagram (Figure 1) the control box generates a $10 \mathrm{kHz}(100 \mu \mathrm{sec})$ clock-cycle. This goes to the delay control, which provides two settable delays (three signals). Two of these signals return to the control module and are integrated into a transmitter control pulse. The transmitter control pulse is sent to the transmitter through optical cable. The width of the pulse determines the length 0.1-5.0 $\mu$ sec of the transmitted ramp. The remaining delayed pulse provides the trigger for the A/D converter boards.

The delay module generates a $500 \mathrm{MHz}$ (2 ns) sampling clock. The delay module provides a sequence of $\mathrm{N}$ sampling clocks ( $2 \mathrm{~ns})$, where $\mathrm{N}$ is the number of sample points (sampling intervals). This sequence is repeated $M$ times, where $M$ is the number of stacks (summations to reduce random noise). When complete, the A/D board is ready to send a record containing the summed sample points to the computer for display and/or storage.

The receiver uses an attenuator and filter at the front of the received signal path to adjust the amplitude and reject interference from broadcast signals, if necessary. The signal is conditioned by a true logarithmic amplifier to compress the dynamic range. The electrical signal is converted to an optical analog signal using a laser diode. The signal passes through a fiber optic cable and is converted back to an electrical signal. The electrical signal then passes through an inverting amplifier, an attenuator, and a computer-controlled adjustable gain amplifier before reaching the A/D boards.

The digitized received data are combined with a header that incorporates GPS, time, position encoder information, attenuation, filter, and antenna orientation. This information is both displayed to the user and saved in a file.

Final Report 10/21/2003

VETEM Survey of Pit 4 and Pit 10

RWMC, INEEL
United States Geological Survey

Crustal Imaging and Characterization Team

Page 2 
The storage memory in the computer are non-volatile solid state drives. These are used to avoid any problems that may occur from vibration and shock. The GPS system incorporates an Ashtech model G12E-RTK with Ashtech base station model G12E-RTK. GPS control and data transfer occurs via an RS-232 link to the computer.

\section{Data acquisition software}

The system is controlled by a Pentium-based PC running Windows 95. The controlling software used Borland $\mathrm{C}++$ graphics libraries to display the data in real time. The program also controls the A/D boards, delay module, programmable attenuator, optical wheel encoder, and the GPS. Information input into the program includes the number of sample points, number of averages, sensitivity of the programmable attenuator, orientation of the $\mathrm{Rx}$ loop, $\mathrm{Rx}$ attenuator settings at the electronics console, filter configuration at the Rx, pulse width of the Tx signal, site name, line number, and file name. This is repeated up to four times to provide four independent data streams acquired sequentially. The user inputs information into the program using a Windows based (Graphical User Interface) GUI dialog that was written in Microsoft Visual C++. Figure 2 is a flow chart diagramming the input information into the GUI dialog. Figure 3 is a display of the VETEM dialog. After this work was completed the data acquisition software was ported to LabVIEW TM.

\section{ATV-towed platform}

The ATV-towed platform (Figure 4) is composed of four components: (1) the non-metallic fiberglass cart and antennas, (2) the ATV, (3) the electronics, and (4) the generator. Figure 5 is a schematic diagram of the VETEM ATV-towed platform.

The non-metallic fiberglass cart is approximately $4 \mathrm{~m}(14 \mathrm{ft})$ long and $1.5 \mathrm{~m}(5 \mathrm{ft})$ wide. The cart is composed of extruded fiberglass material with negligible metallic fasteners. The cart is assembled with fiberglass bolts and epoxy. The VETEM cart is attached to the ATV via a $3 \mathrm{~m}$ long $2 \times 2$ in. fiberglass towbar.

The antennas are $30 \mathrm{in}$. square loops with the Tx leading and the Rx 2 meters (center to center) behind the Tx loop. These antennas have a 1 in. wide strip of copper strap affixed to $2 \times 2$ in. cross-section square fiberglass frames. The copper is terminated with banana plugs that connect to the Rx and Tx electronics packages. In Figure 4, note that the $\mathrm{Rx}$ antenna is composed of two $30 \mathrm{in}$. square loops that are permanently mounted perpendicular to each other. The Rx electronics allows recording both coplanar (both the $\mathrm{Tx}$ and $\mathrm{Rx}$ oriented horizontal) and perpendicular (with the Tx horizontal and the Rx vertical) data. The perpendicular configuration was used for all data in this report.

The towing vehicle is a Suzuki 4WD Quadrunner 250cc ATV. The ATV is operated in the lowest gear with the speed controlled by the operator.

Mounted on the ATV are the electronics that control the VETEM system. The computer, control unit, delay unit, GPS rover receiver, and optoelectronics are shock mounted in a weather-proof fiberglass shipping crate. External to the shipping crate are the flat-screen LCD monitor, keyboard, and touch pad that are used for data display and system control.

Final Report 10/21/2003

VETEM Survey of Pit 4 and Pit 10

RWMC, INEEL
United States Geological Survey

Crustal Imaging and Characterization Team

Page 3 
Power for the system is provided by a Honda EU1000I generator that is mounted at the front of the ATV. The generator is connected in series to an APC Back-UPS 650 uninterruptible power supply and a GFCI (ground-fault circuit interrupter).

Since the completion of this work the GPS has been upgraded to a Javad Legacy, and the ATV was replaced by a small tractor.

\section{GPS-positioning}

The positioning of the data was accomplished using an Ashtech G12E-RTK (realtime kinematic) system and an incremental optical encoder. The G12E-RTK GPS (GPSonly) system is capable of producing sub-meter accuracy typically on the order of $20 \mathrm{~cm}$, with accuracy to $1 \mathrm{~cm}$ in good conditions (Magellan, 1998). "Good conditions" means an open sky, with an unrestricted view of seven or more GPS satellites. The RTK system uses a carrier signal in addition to the code signal from the satellites. The carrier signal is transmitted from a GPS base station through a radio link and is received at the rover (remote GPS receiver). The rover GPS antenna is mounted on a mast at the front of the fiberglass VETEM cart and is linked to the GPS receiver by a coaxial cable. The GPS antenna is not mounted in the center of the Tx and Rx array because the coaxial cable would cause coupling interference with the Rx. Recorded positions are numerically shifted to the center of the Tx and Rx antennas during data processing. The GPS rover receiver is controlled by the computer and is set up to provide information on an asneeded basis (queried by the computer). The GPS base station is set up over a known control point and the known coordinates are entered. At the beginning of each day the GPS base station is started and is left to operate unattended for the duration of data collection.

The GPS provides a message containing time, position, and system information (number of satellites, precision, error). The message is used to monitor the type of GPS position that is being received. One of four possible flags is set: 1) no-GPS, 2) autonomous, 3) RTK-float, and 4) RTK-fixed. The type of position flag is recorded in the headers to be used in the data processing. A description of the GPS position quality is included in a later section of this report.

In addition to the GPS positioning, a BEI Incremental Optical Encoder model $\mathrm{H} 25$, mounted on the left rear wheel hub of the ATV, provides calibrated incremental digital marks to the control box that counts the pulses and converts the sum to a digital signal read by the computer. This information supplies independent distance-traversed measurements that can be integrated into the data positioning.

\section{Data storage}

Data storage on the ATV-towed platform is accomplished by using a SanDisk Flash Drive model \# SD35B-192. This unit is solid state memory with robust environmental specifications including an operating temperature range of $0^{\circ}$ to $60^{\circ} \mathrm{C}$, operating vibration level of $15 \mathrm{G}$ peak-to-peak, and a operational shock rating of $1000 \mathrm{G}$ max. Data are written to this drive during data collection. Periodically the data are manually transferred to an external Iomega Jaz drive as a backup. 


\section{Site Description}

The Radioactive Waste Management Complex (RWMC) is located in the southwest corner of the Idaho National Engineering and Environmental Laboratory in Eastern Idaho (Figure 6). The RWMC is a 168 acre area used to manage solid transuranic-contaminated waste and solid low-level radioactive waste generated in national defense and research programs. Within the RWMC, the Subsurface Disposal Area (SDA) is an 88 acre area in the western section of the RWMC. It contains an active shallow land burial area for the permanent disposal of solid, low-level waste. The area also contains pits and trenches where mixed transuranic and low-level waste was buried between 1954 and 1970 (Figure 7). Much of the transuranic waste buried at the INEEL consists of contaminated clothing and equipment. This waste was shipped to the INEEL primarily from the Rocky Flats Plant near Golden, CO. The RWMC was established in 1952 as a 13 acre location for storage and disposal of solid radioactive waste. For about two years, only low-level waste was buried at the RWMC. In 1954, Rocky Flats began shipping defense waste with transuranic elements, and by 1957 the original 13 acres were nearly filled. Between 1960 and 1963, the RWMC accepted low-level waste from private sources such as universities, hospitals and research institutes. This service stopped when commercial burial sites for contaminated waste from private industry became available. Waste was disposed in 20 pits, 58 trenches and 21 soil vault rows throughout the SDA. Further information can be obtained from the INEEL web site (http://www.inel.gov/).

The survey area where the USGS prototype VETEM system was deployed is within the area of Pit 4 and Pit 10 of the SDA (Figure 8).

\section{Survey Design and Layout}

A local grid was established for data collection based on the northern most edge of Pit 4, Figure 9. This line was designated line $0 \mathrm{~S}$ for the survey of Pit 4 . The NE Pit 4 marker was designated $0 \mathrm{E}$ for the local grid. Lines were numbered north and south of this line in one meter increments. This local grid was established for ATV guidance only, as the prototype system does not currently provide waypoint guidance. Field personnel kept the driver of the ATV on line via radio communication using a sightline established between an autolevel at the beginning of the local grid line and a reflective target at the end of the line. However, all of the positioning of the VETEM data occurs through the GPS data. The local grid was simply a guide for uniform data coverage. The local grid nomenclature was also used in the file naming convention. A similar local grid was also set up on Pit 10 (Figure 9).

\section{Calibration pad}

A calibration pad was set up in an area of the SDA remote from subsurface waste. The calibration pad consisted of six $4 \times 8 \mathrm{ft}$. sheets of $1 / 16$ in. thick aluminum glued to 4 x $8 \mathrm{ft} .1 \frac{1}{2}$ in. thick high-density foam panels. These were arranged to provide an effective 12 x $16 \mathrm{ft}$. ground plane. The sheets were electrically joined using $2 \mathrm{in}$. wide conductive-adhesive copper tape. The purpose of the calibration pad was to calibrate the response of the VETEM system on a daily basis. The calibrations serve as a baseline for monitoring the performance of the system, and allow for the leveling of the data for any 
base-level offsets that may occur. Figure 10 shows a photograph of the VETEM cart and antennas on the calibration pad.

\section{System settings}

The system was configured to optimize the quality of the data and the density of the data along the traverses. Settings remained constant throughout the survey to provide a constant data set. Table 1 contains the system settings used in the data collection and calibration.

Table 1. VETEM system settings used at INEEL, Pit 4 and Pit 10

\begin{tabular}{|l|l|l|l|l|l|l|l|l|l|l|l|}
\hline $\begin{array}{l}\text { Data } \\
\text { Series }\end{array}$ & $\begin{array}{l}\text { Record } \\
\text { Length }\end{array}$ & $\begin{array}{l}\text { Records } \\
\text { Averaged }\end{array}$ & $\begin{array}{l}\text { Sensitivity } \\
(\mathrm{mV})\end{array}$ & $\begin{array}{l}\text { Pulse } \\
\text { Width } \\
(\mu \mathrm{s})\end{array}$ & $\begin{array}{l}\text { Tx Rx } \\
\text { Spacing } \\
(\mathrm{m})\end{array}$ & $\begin{array}{l}\text { Tx } \\
\text { Loop }\end{array}$ & $\begin{array}{l}\text { Console } \\
\text { Att. }(\mathrm{dB})\end{array}$ & $\begin{array}{l}\text { Rx } \\
\text { Loop }\end{array}$ & $\begin{array}{l}\text { Rx } \\
\text { Att.(dB) }\end{array}$ & $\begin{array}{l}\text { Rx } \\
\text { Filter } \\
(\mathrm{MHz})\end{array}$ & $\begin{array}{l}\text { Loop } \\
\text { Height } \\
(\mathrm{m})\end{array}$ \\
\hline $\begin{array}{l}\text { High } \\
\text { gain } \\
\text { Data }\end{array}$ & 8192 & 2048 & 800 & 2.14 & 2.0 & $\mathrm{H}$ & 20 & $\mathrm{~V}$ & 10 & 50 & 0.733 \\
\hline $\begin{array}{l}\text { Low } \\
\text { gain } \\
\text { Data }\end{array}$ & 8192 & 2048 & 800 & 2.14 & 2.0 & $\mathrm{H}$ & 20 & $\mathrm{~V}$ & 30 & 50 & 0.733 \\
\hline $\begin{array}{l}\text { High } \\
\text { gain } \\
\text { Cal. }\end{array}$ & 8192 & 2048 & 800 & 2.14 & 2.0 & $\mathrm{H}$ & 20 & $\mathrm{~V}$ & 50 & 50 & 0.733 \\
\hline $\begin{array}{l}\text { Low } \\
\text { gain } \\
\text { Cal. }\end{array}$ & 8192 & 2048 & 800 & 2.14 & 2.0 & $\mathrm{H}$ & 20 & $\mathrm{~V}$ & 70 & 50 & 0.733 \\
\hline
\end{tabular}

Two gain settings were used for data collection and another two gain settings were used for calibration of the VETEM system. Data at these gain settings were collected sequentially during the traverse of the area and during calibration. The lowgain setting provided a linear response of the system while the transmitter was on and right after turn-off. The high gain amplified the signal over the time decay region. The high gain and the low gain data can be combined to provide a composite waveform with linear characteristics throughout the time series. The levels of the attenuators, amplifiers, and filter bandwidth in the system were chosen to optimize data quality for this survey. Data were collected with the horizontal (H) Tx and vertical (V) Rx configuration only, because this configuration proved effective over Pit 9. The height of the loops above ground was set for clearance of obstacles and rough ground within the survey area, but still allowed high resolution imaging of the subsurface.

\section{GPS and positioning}

The GPS positioning data were collected using the Ashtech G12E-RTK base station and rover. The base station was set up on well cap W-13 B. (Latitude $43^{\circ} 29^{\prime}$ $57.32482^{\prime \prime} \mathrm{N}$, Longitude $113^{\circ} 02^{\prime} 44.19628^{\prime \prime} \mathrm{W}$ ) and, as stated earlier, the rover was mounted to the towed platform. The GPS was operated in the RTK mode in either RTKfloat or RTK-fixed. The key to understanding the operation of the RTK GPS is the fact that the receiver can measure the fractional part of the carrier phase to centimeter accuracy. It derives the integer number of full carrier-phase wavelengths by processing both the carrier and code phase measurements. This process of deriving the integer numbers is known as integer ambiguity resolution or carrier phase initialization. This 
carrier phase initialization is only necessary following power-on, or after the receiver has lost lock on the satellites. Once the receiver has initialized it will provide centimeterlevel accuracy, while moving, in real time. The required time for carrier phase initialization is dependent on the baseline length (distance between the base station GPS and the rover), number of satellites in view, and the required reliability. During carrier phase initialization the receiver is said to be in "float" mode. Once the initialization is complete the receiver is said to be in "fixed" mode.

When the GPS receiver is in float mode, the accuracy will range from Differential GPS accuracy of $1 \mathrm{~m}$ down to sub-decimeter (Ashtech, 1998). The longer the receiver has been in float mode, the higher the accuracy. The convergence to $20 \mathrm{~cm}$ accuracy takes approximately five minutes, convergence to $10 \mathrm{~cm}$ accuracy requires approximately ten minutes (Ashtech, 1998). Convergence time is a function of baseline length, the number of satellites in view, and their positions in the sky. When the receiver fixes integers (RTK fixed mode), accuracy makes an order-of-magnitude change to centimeter level (Ashtech, 1998). Figure 11 is a plot from Ashtech showing convergence of float solution following GPS system resets.

Latency of the GPS positions is another issue that will affect the positions. There are two types of latency: base data latency, and position latency. Base data latency is the delay between when the base station measures the GPS signals and when the remote receiver receives the messages. This latency is a function of the baud rate of the radio link and the length of the baseline. To minimize this latency the data need to be transmitted at 4800 baud or faster for the system used in the VETEM (Ashtech, 1998). The rate that was used during this survey was equal to 9600 baud over a short base line. This provided an update rate of $5 \mathrm{~Hz}$. The other latency is position latency, which is the delay between the time at which the remote receiver measures the GPS signals and the time at which the position is available at the serial port. This is the delay in measuring and recording the position. Position latency is typically between 50 and $100 \mathrm{~ms}$, and varies with number of satellites in view.

Position accuracy for the data collected at the INEEL using the prototype VETEM system included approximately $85 \%$ of the positions with RTK-float mode accuracy and the remaining with RTK-fixed mode accuracy. This distribution of accuracy is a consequence of the availability and position of the satellites during the survey. The Ashtech G12E-RTK is a single frequency GPS-only system. It does not use the information from the dual frequency transmissions from the GPS constellation or the Russian GLONASS constellation. Subsequent to this study the VETEM's GPS was upgraded to a Javad Legacy system that uses dual frequency GPS and GLONASS.

In order to check our equipment and to survey within the bounds of the Pit 4 and Pit 10, INEEL personnel provided the USGS with coordinates for the corners of Pit 4 and Pit 10 (Table 2). The USGS prototype VETEM system agreed out with the known positions within the accuracy stated by Ashtech for both RTK-float mode and RTK-fixed mode. 
Table 2. Coordinates for the corners of Pit 4 and Pit $10^{1}$

\begin{tabular}{|l|l|l|}
\hline Survey Point & East (UTM) (meters) & North (UTM) (meters) \\
\hline NE Pit4 & 334656.1821 & 4818369.392 \\
\hline NW Pit4 & 334358.9295 & 4818387.733 \\
\hline SW Pit4 & 334361.6941 & 4818353.885 \\
\hline SE Pit4 & 334636.3889 & 4818334.818 \\
\hline NE Pit 10 & 334696.3264 & 4818323.651 \\
\hline NW Pit10 & 334361.6254 & 4818345.964 \\
\hline SW Pit 10 & 334364.5063 & 4818325.827 \\
\hline SE Pit 10 & 334689.0723 & 4818294.457 \\
\hline S Pit10 & 334443.2504 & 4818304.752 \\
\hline Base (GPS) & 334620.1016 & 4818291.465 \\
\hline
\end{tabular}

\section{Data archiving}

Data collected each day were backed up to an Iomega Jaz disk and to optical CDR's. These CD-R's archive the original data and provide a medium that is not subject to magnetic damage or inadvertent corruption by changing or editing. Two copies of the field data were made every night and stored in separate locations.

\section{Data Collection}

\section{Daily data collection}

Data presented in this report were collected on the following days 5-10-00, 5-12$00,5-13-00,5-15-00,5-17-00,5-18-00,5-19-00$, and 5-22-00. Figure 12 is a plot of the areas covered in the survey for each specific day. The areas were surveyed in order of importance. Also note that on 5-19-00 the area between Pit 4 and Pit 10 was surveyed, because a PVC pipe present at the beginning of the survey was removed. Regarding the GPS positions for the data collected on 5-10-00, a glitch in the GPS rover did not allow the GPS base station's preprogrammed position to be transmitted. As a result, the base station transmitted an autonomous GPS position to the rover and that position was used for the data collection throughout 5-10-00. This autonomous position caused a static shift in the position data for that day. To correct this particular problem the static shift was removed from the data and checked against repeat traverse lines on 5-12-00. Corrective actions were taken on 5-12-00 to prevent any further problems with the GPS by directly programming the GPS base stations coordinates into the GPS rover. All other data were double-checked to verify that no static shifts occurred by reoccupying known survey points throughout the survey.

\section{Daily calibration}

Each day calibration measurements were completed at the beginning and end of the day. The platform was positioned at approximately the same spot on the pad and approximately 50 records were recorded. These data were archived and backed up in the same manner that survey data were handled.

\footnotetext{
${ }^{1}$ These values are converted to UTM, NAD83, Zone 12, meters from the original coordinates supplied by site personnel that were NAD 83 State Plane, ID East 1101, U.S. Feet

Final Report 10/21/2003

VETEM Survey of Pit 4 and Pit 10

RWMC, INEEL
} 


\section{On-site obstacles and logistics}

Within the survey area, several obstacles had to be avoided. These consisted of a power cable on the ground surface, shed-like structures, sign posts, ditches, piping and plumbing, monitoring wells, and equipment. The most serious obstacle was a power cable on the surface that cut across Pit 4 (Figure 12 and Figure 13). Data were collected over the power cable on day 5-13-00 only. Site safety personnel then directed that we not drive over the power cable. After 5-13-00 the ATV and the VETEM cart were not driven over the cable. As a consequence, the survey area lacks data for approximately 10 meters on either side of the cable. The $10 \mathrm{~m}$ is related to the length of the cart and ATV, approximately $8 \mathrm{~m}$ long, plus the distance required to turn and position the ATV. Another obstacle was equipment parked on the east side of Pit 4 (Figure 14). Other obstacles included the structures at the ends of Pit 4, the piping and plumbing between Pit 4 and Pit 10, and various signs (Figure 15, Figure 16). Data images show blanked out areas where the ATV-towed platform could not enter.

Initially, the local grid was laid out by the field personnel, who then walked the area to identify any hazards and to appropriately flag areas to be avoided. Data were then collected in traverses, as stated earlier, running approximately east-west separated by one meter (Figure 17). The exception were areas containing obstacles. The data were only collected in one direction, from east to west, to avoid herringbone patterns in the images. After the data were collected for one traverse, which composed one to five files, the ATV and the platform were driven back to the eastern end of the survey area, and the next traverse was collected. During the time that it took the operator to drive the VETEM system back to the eastern end of the survey area, the other field personnel would reposition the autolevel and the reflective target at the ends of the line to establish the new sightline along the next traverse. This procedure was repeated until the data storage drive was nearly full, at which time the drive was backed up to an Iomega Jaz drive and to a portable field computer. Usually at these intervals field personnel would refuel the generator and ATV.

At the beginning of each day a safety briefing and daily work plan review was conducted with all field personnel. A typical field day consisted of approximately 6 hours of data collection and 1.5 hours of setup and 1.5 hours of demobilization. Sporadic delays occurred throughout the survey due to equipment malfunctions and adjustments, and to inclement weather. Field personnel noted all field conditions and equipment problems in the field notebook.

\section{Data Processing}

\section{Positioning}

VETEM field data files were input to the VETEM Preprocessor, an application written in Research Systems' Interactive Data Language (IDL). The GPS data were screened according to fix quality. "GPS_FIX" and "GPS_FLOAT" were passed through, while "GPS_AUTONOMOUS" and "NO_GPS" are rejected due to inherent inaccuracy. The latitude and longitude data from the Ashtech unit were recorded in "ddmm.mmmmmm" and "dddmm.mmmmmm" format respectivitly. The preprocessor parsed and converted these data into standard decimal degree "ddd.ddddddddddd" format. The latitude and longitude coordinates (WGS84) were then converted into universal 
transverse Mercator (UTM Zone 12, NAD83 meters) coordinates using the computer program Corpscon, Version 5.11.08, 1997, developed and freely distributed by the U.S. Army Corps of Engineers, Topographic Engineering Center, Alexandria, Virginia, 22315-3864. The data were also corrected for the GPS antenna to center of the antenna array offset, approximate slope of the ground and antenna height, and data latency.

\section{Data parsing}

To reduce file size and conserve computer memory, the data were winnowed from 8192 samples per waveform at 2 ns per sample (16384 ns per record), to 1250 samples per waveform at $8 \mathrm{~ns}$ per sample (10000 ns per record). Thus the data passed to the image processor was a subsample of the original (1:4), and truncated the late times (greater than $10000 \mathrm{~ns}$ ). For the purposes of data display and two-dimensional mapping, this reduction had no deleterious effect on the final result. A waveform average was calculated for each field data file, in which records containing extreme values (greater than 1.6 standard deviation) are excluded from the average. These waveform averages were tagged with a unique identifier in order for them to be associated with waveforms from the corresponding data line.

Data from numerous lines over a distinct area (for example: Pit 4, Pit 10, the trench) were written to a structured, random access data file, termed an associated variable (ASV) file in IDL. Combining the separate ASV files can produce an ASV file for the entire site survey.

\section{Gridding and data display}

The GUI of the image processor, written in IDL, displayed the data in a primary pane of 300 by 300 pixels. Data coordinates must be scaled and binned to fit within the display window. In the cases of Pits 4 and 10, the spatial density exceeded the pixel density, and consequently not all the data points were displayed. A zoom capability in the image processor allowed the operator to select an area with an adjustable size box. Data windowed by the box were scaled and binned into the display pane. For final map preparation, the image in the display pane was exported to an ASCII file for gridding and mapping by the computer program Surfer (Golden Software).

The image processor also generated outlines of missed areas and output a list of coordinate pairs suitable for constructing blanking (BLN) files for Surfer. A blanking file has the effect of truncating interpolation at the edges of data-containing areas. The Surfer program was used to post data points, to blank out areas containing no data, and to overlay base maps.

\section{AVI files}

Time-lapse movies (AVI file format) of VETEM data were generated by creating a number of time slices at a given time interval. AVI files were made of the entire survey starting at $1824 \mathrm{~ns}$ and ending at $9248 \mathrm{~ns}$, with image frames every $64 \mathrm{~ns}$. Two AVI files were created: one used a normal pixel distribution for the color table, and the other used a histogram-equalized pixel distribution. The histogram equalized images accentuated 
contrast differences, making conductivity anomalies visible, even to late times. These AVI files can be viewed on a computer by a number of widely available viewers. AVI files are contained within Appendix B.

\section{Time Slices Examples}

The following sections show results of image processing of the VETEM data collected over Pit 4 and Pit 10. The images are of selected time slices from the recorded time series for each record. For example, a time slice of Pit 4 and Pit 10 at 3800 ns would display the amplitudes of all the time series at $3800 \mathrm{~ns}$ only, showing how the amplitude varies with location. The images include slices when the Tx is on (on-time) and after the Tx is turned off (transient response). Figure 18 is a selected average received time series from the data set. Note the behavior during the time the Tx is on versus the decay after the $\mathrm{Tx}$ is turned off. The included images are only for the high gain perpendicular antenna configuration. The data are displayed in UTM coordinates, NAD 83, Zone 12, in meters. The pit corners, as tabulated above, are plotted on the VETEM data for reference. The data that are displayed in the following are raw data. No leveling or system response removal has been applied. The images were smoothed, by using an interpolation routine, between the $0.5 \mathrm{~m}$ gridding spacing. Images are displayed for the complete survey area as well as specific areas within the survey area including: Pit 4, Pit 10, the trench area north of Pit 4, the depleted uranium focus area, the Am/ $\mathrm{Np}$ focus area, and the organic sludge focus area. For some of the images the locations of the proposed probe holes are posted for reference.

Each time slice images is has a unique color table that has been manually stretched and adjusted to reveal the amplitude variations within the data. Hotter colors (red) indicate regions that are relatively conductive and/or shallow targets, and the cooler colors (blue) indicate less relatively conductive and/or deeper targets. Note, before Tx turn-off the lower relative amplitude will be the more conductive target response. This reverses after Tx turn-off and higher relative amplitude areas are the stronger target responses. This polarity reversal has been taken into account by reversing the color table. The data were plotted at the center of the Tx-Rx loop array. The images could be slightly shifted along the traverses because the maximum response from a finite target may not coincide with the plotting point. These slight shifts could occur at edges of conductive objects, and can be a function or combination of depth of the conductive object, antenna spacing, and direction of transverse. Discretion should be used in examining the details of these raw images, especially at edges of targets. Digital images of the results of this report are contained within Appendix C.

\section{Pit 4 and Pit 10}

Figures 19 through 22 are time slice images of the entire data set at 1500, 3800, 5000, and $7000 \mathrm{~ns}$, respectively. Figure 19 is a time slice of the data when the Tx is still transmitting. Figures 20 through 22 are time slices after the Tx has turned off (transient).

Important features in Figure 19 include conductive targets throughout the pits and in the trench area to the north of Pit 4. The eastern area of Pit 4 contains an area of relative high amplitudes. This area does not follow the pit boundaries. This anomaly 
may be caused by the superposition of responses from subsurface conductive targets and a relatively conductive surface layer(s). The overall image appears saturated in the regions of targets while the Tx is on as compared to the target response after Tx turn-off. In the time slices after the Tx has shut off, this anomaly vanishes and the subsurface targets can be distinguished from the earth response. Within this image the power cables are visible in Pit 4. There is also a minor level shift in the data for Pit 10 that can be observed in approximately the center of the pit running east-west. This is a raw data artifact from the electronic instrumentation. Note that these data have not been processed to level the data or remove any instrumentation drifts. These artifacts are small.

Figures 20 through 22 are images of the VETEM response for increasingly later times after the Tx has turned off. These images show the distribution of relatively conductive targets throughout the pits and trench areas. Pit 4 contains strong responses to conductive, presumably metal, targets. These strong responses persist throughout the time series to $7000 \mathrm{~ns}$ (Figure 22). The images of the transient response clearly demonstrate time dependence in the response of the VETEM system to the conductive subsurface targets. Areas relatively devoid of conductive targets, or that contain relatively deep targets, also are distributed throughout the pits, notably an area just west of the center of Pit 4 and at the eastern part of our coverage of Pit 10. Responses are observed in the trench area north of Pit 4 and in the region south of Pit 10. As with the image made from data recorded while the $\mathrm{Tx}$ is on, the power cables are visible within Pit 4. There is also a minor leveling artifact at the top of Pit 4. This artifact is caused by a level shift that has not been compensated for and is not related to the top of the pit.

The overall amplitude of the response of the data in Pit 10 is less then the response in Pit 4. For this reason the areas were split up to better examine the subtleties of the response without a color table bias to strong responses in unrelated areas. These results are presented below.

\section{Pit 4}

Figure 23 is a series of three time slices of Pit 4 after the Tx has turned off (transient response). The time slice images are for 3800, 5000, and $7000 \mathrm{~ns}$. These images display a strong response to conductive targets at the western side of Pit 4 as well as in the center of Pit 4. There is a much more subtle response in the eastern portion of Pit 4 with only a few targets persisting throughout the time series. This persistence would indicate very good conductors, such as metallic waste. The responses in Pit 4 also clearly demonstrate distinct separate subsurface conductors distributed throughout the pit. The power lines are clearly observable in Pit 4 . These power line responses should be ignored, as the strong response caused an oscillation in the data. However, this is a very local effect and the data that are not taken directly over the power lines show no negative effects. A closer examination of the eastern portion of Pit 4 (organic sludge focus area) will be covered below.

\section{Pit 10}

Figure 24 is a sequence of three time slice images of Pit 10 after Tx turn off for 3800,5000 , and $7000 \mathrm{~ns}$. As noted above, there is a time dependence of the response of 
the VETEM system. The benefit of separating the areas becomes apparent as the color table distribution brings out more detail within Pit 10. The western area of Pit 10 displays a strong response that persists throughout the time series. There is a sharp boundary on the eastern edge of the area surveyed in Pit 10. The area east of this boundary is relatively less responsive with the exception of a small anomaly at approximately easting 334635, and northing 4818310. It is important to note that for the $7000 \mathrm{~ns}$ time slice the noise floor in the data is increasing. However, the late time slice clearly demonstrates that the more conductive targets are persisting into late time. A closer examination of the depleted uranium focus area and the $\mathrm{Am} / \mathrm{Np}$ focus area are included below.

\section{Trench area}

Figure 25 is a time slice image of the trench area north of Pit 4 at 3800 ns. This image shows several discrete responses throughout the region. The break in the middle of the plot is the area where the power cable crossed Pit 4. To the east of this area this image shows four discrete round responses between easting 334620 and easting 334635 . There are also three smaller responses to the east of there around easting 334650 to easting 334665. There are several larger round shaped responses in the region from easting 334405 to easting 334450, and a series of responses that blend together from easting 334500 to easting 334560 .

\section{Depleted uranium focus area}

Figures 26 through 28 are selected time slice images for 3800, 5000, and $7000 \mathrm{~ns}$ from the depleted uranium focus area. For each time slice, probe holes DU-1 through DU-8, coordinates provided by Bechtel BWXT Idaho personnel, are posted on the VETEM images. Strong time dependence is exhibited in the data from the depleted uranium focus area, notable in the region of DU-8 where the relative intensity of the response decays away between 3800 ns and 5000 ns, Figure 26 and Figure 27 respectively. In the area west of DU-8 at approximately easting 334370 and northing 4818338 the relative intensity of the response increases with time compared to the other responses in the area (Figure 28). As was noted in other images, strong conductors persist through the time series. This persistence is observed in the areas of easting 334387, northing 4818329, and easting 334377, northing 4818324 within the depleted uranium focus area.

\section{Am/Np focus area}

Figures 29 through 31 are selected time slice images for 3800, 5000, and $7000 \mathrm{~ns}$ from the Am/ $\mathrm{Np}$ focus area. For each time slice, probe holes 741-1 through 741-9, coordinates provided by Bechtel BWXT Idaho personnel, are posted on the VETEM data. Time dependence is exhibited in the data from Am/Np focus area. However, the strong anomalies within the area persist throughout the time series and do not change in relative intensity as did some of the areas in the depleted uranium focus area. The most notable anomalies in the Am/Np focus area are located at easting 334493, northing 4818320, and easting 334477, northing 4818320. These anomalies persist with decreasing amplitude throughout the time series. 


\section{Organic sludge focus area}

Figure 32 and Figure 33 are selected time slice images for 4080 and 7000 ns from the organic sludge focus area. For each time slice, geoprobe holes 743-1 through 743-31, coordinates provided by Bechtel BWXT Idaho personnel, are posted on the VETEM data. Time dependence is again exhibited in the data from the organic sludge focus area. Figure 32 contains several anomalies. Specifically there are four distinct features at the northern edge of Figure 32 from easting 334580 to 334626, northing 4818368. These anomalies persist through the time series to $7000 \mathrm{~ns}$ (Figure 33). There are several other notable anomalies within the focus area including a lineament that tracks probe holes 743-1 through 743-8. Another linear anomaly extends down from the large anomaly at easting 334610, northing 4818368, through probe hole 743-17 and 743-18 down to approximately easting 334634, northing 4818342. These linear features have almost decayed away in Figure 33 at 7000 ns.

\section{Conclusions}

The USGS prototype VETEM system was successfully deployed over Pit 4 and Pit 10 in the SDA of the RWMC at the INEEL from May 10 through May 22, 2000. The VETEM system is specifically designed to penetrate conductive soils where GPR can not be used. The VETEM system also is unique as the only system that records both the transmitted waveform as well as the transient part of the signal. The VETEM also operates at much earlier times than traditional TDEM systems. This field deployment was the first use of the new VETEM ATV-towed platform, with an integrated RTK-GPS system that provides positioning at a sub-decimeter level. A perpendicular antenna loop array was implemented, with sequential collection of both a high and a low gain time series. These high and low gain time series can be combined to reconstitute a waveform.

Pit 4 and Pit 10 were completely surveyed, as site access permitted, within the allotted timeframe and despite problems encountered with prototype hardware and inclement weather. The uniformly high quality data obtained over the study areas have yielded high resolution time-slice images of subsurface conductivity variations. For this report images have been produced of selected time slices over the areas of Pit 4 and Pit 10. These time slice images are of raw data for the high gain time series. They have not been leveled nor has the system response been removed. The data appear to be robust with good coverage and with good responses over the surveyed areas. These results indicate that the VETEM system is collecting data throughout the time series and can detect many conductive targets within the subsurface. Within the surveyed area subsets of the data have been imaged to produce high-resolution maps of specific areas of interest: including the depleted uranium focus area, $\mathrm{Am} / \mathrm{Np}$ focus area, and the organic sludge focus area.

\section{References}

Ashtech, 1998, GG24 OEM Board \& Sensor GPS+Glonass, Reference Manual , January, 1998, Ashtech Inc., Sunnyvale, CA.

Magellan, 1998, G12E-RTK Supplement, P/N 630228 Revision A, March 1998, Magellan Corporation, Sunnyvale, CA.

Final Report 10/21/2003

VETEM Survey of Pit 4 and Pit 10

RWMC, INEEL
United States Geological Survey

Crustal Imaging and Characterization Team

Page 14 
Final Report 10/21/2003

VETEM Survey of Pit 4 and Pit 10

RWMC, INEEL
United States Geological Survey Crustal Imaging and Characterization Team 
Figures

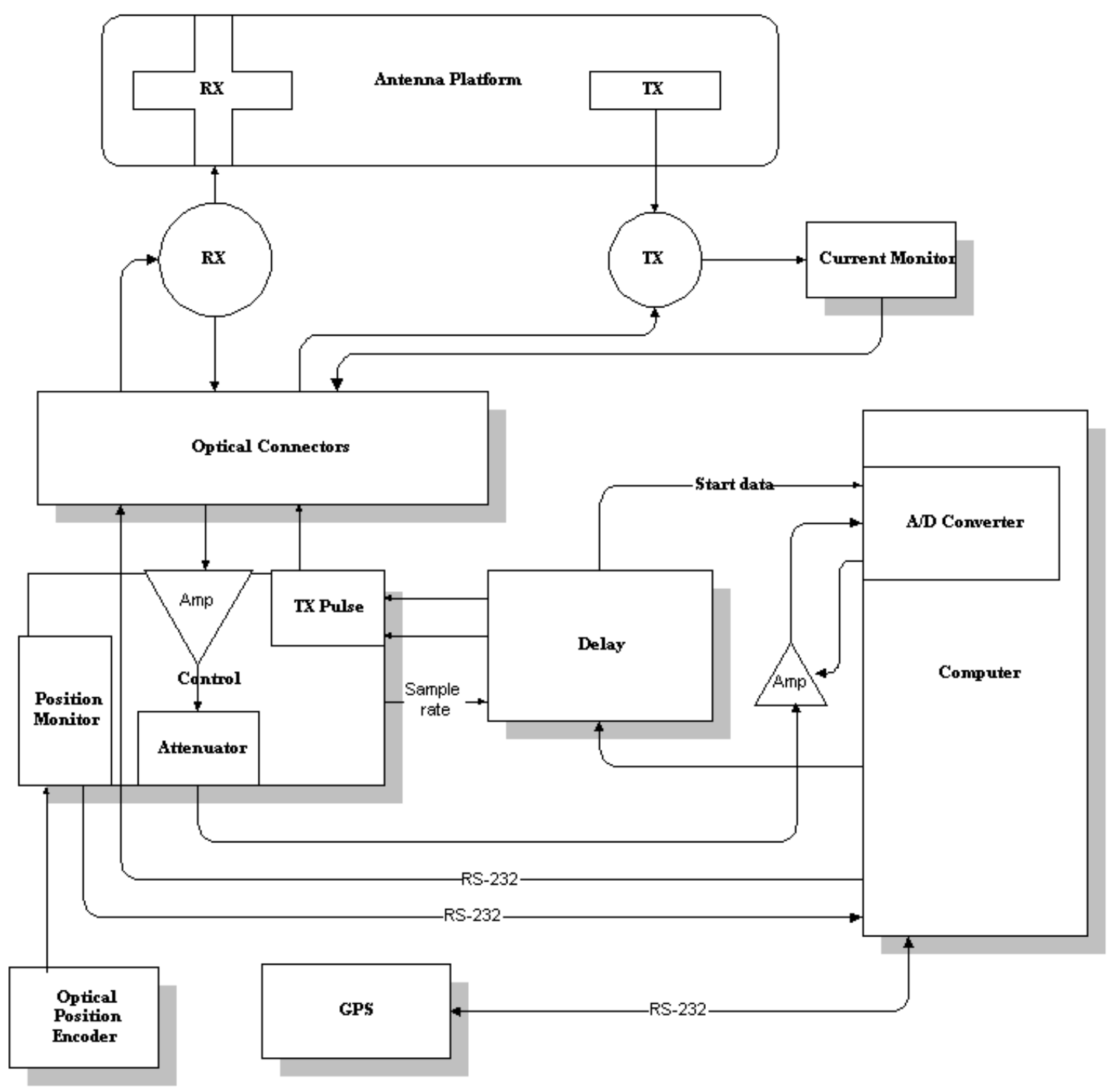

Figure 1 Flow chart of the VETEM electronics. 


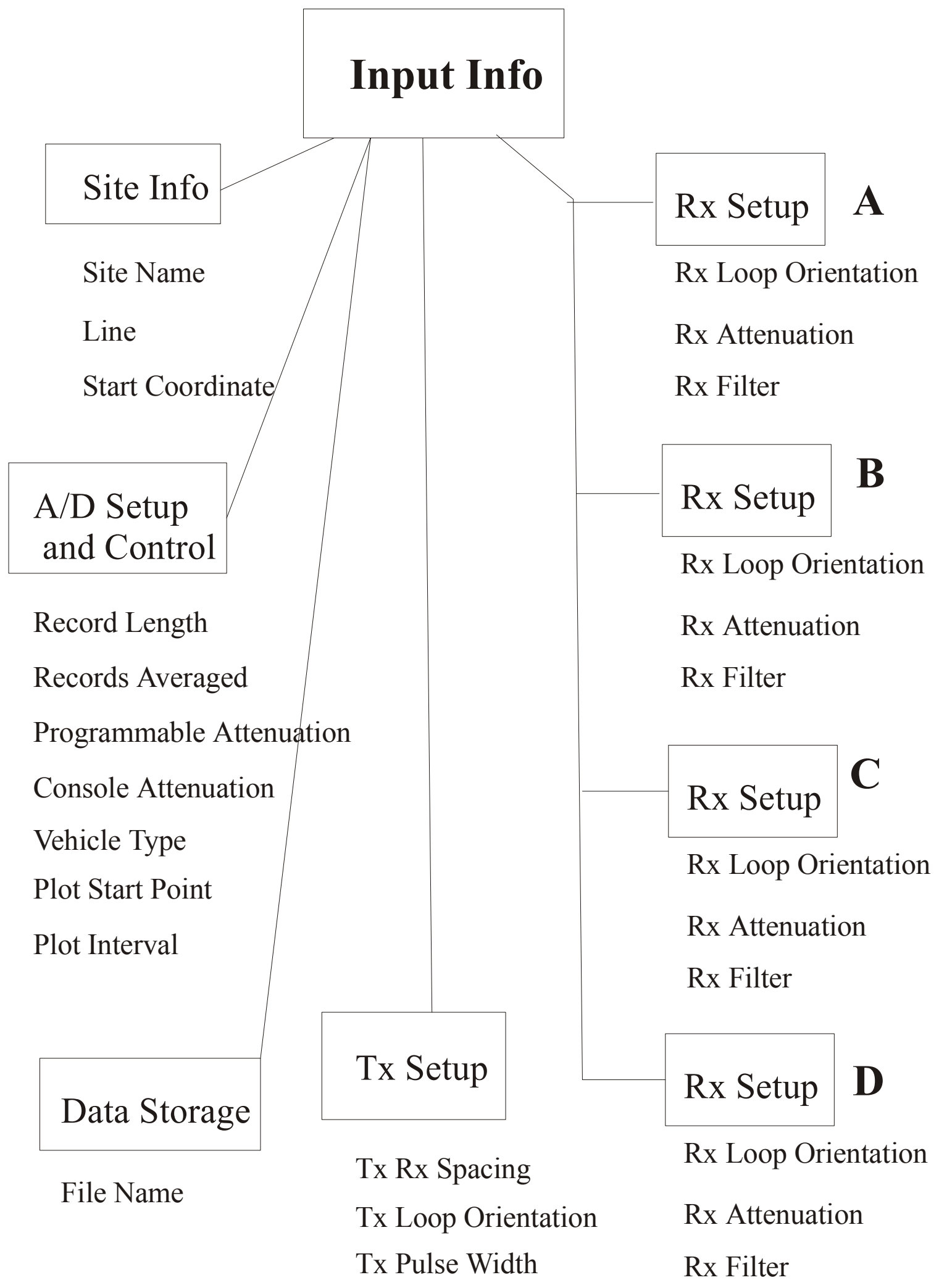

Figure 2 Flow chart of the input information required for the VETEM program. 


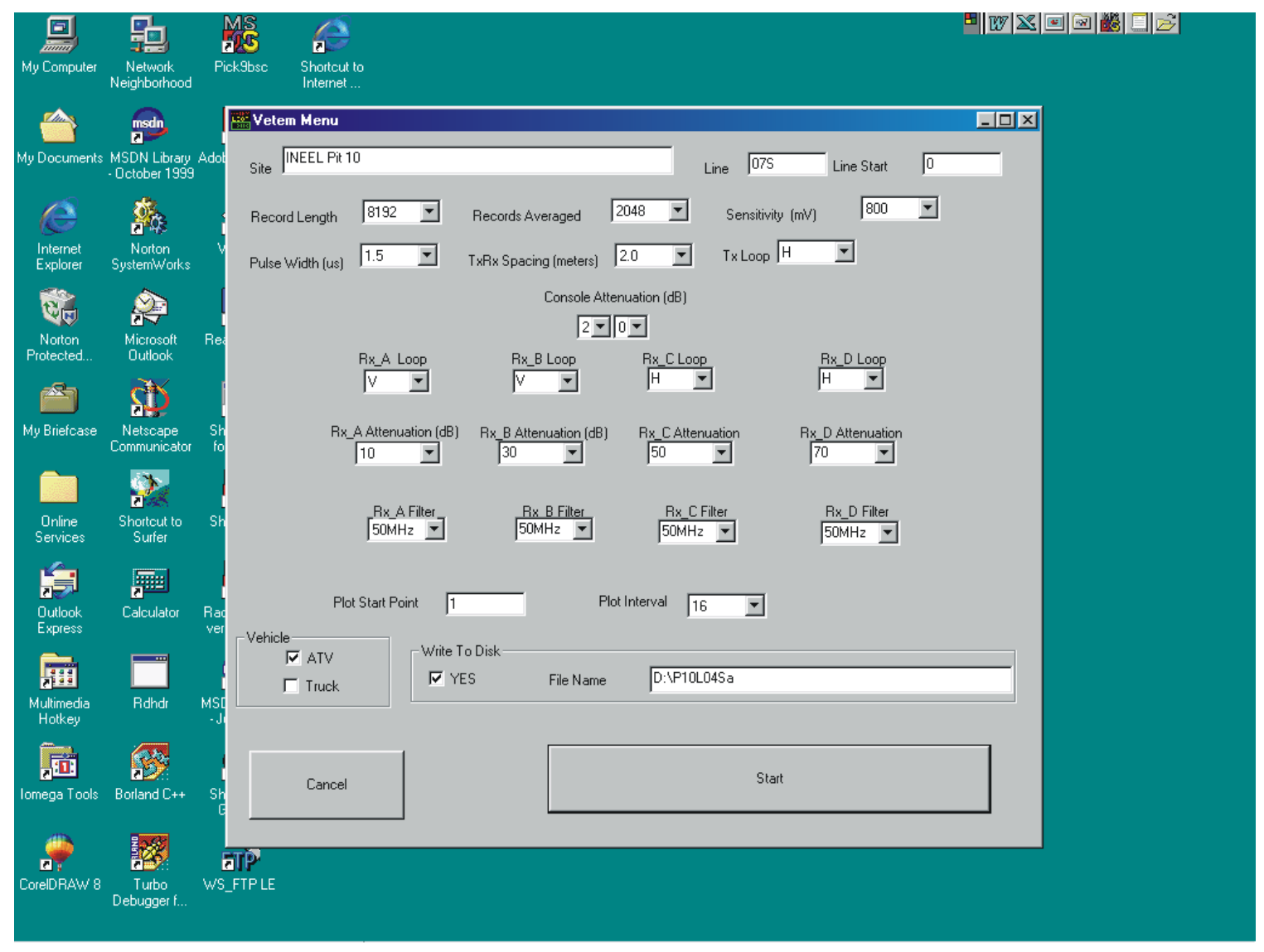

Figure 3 Display of the VETEM dialog. 


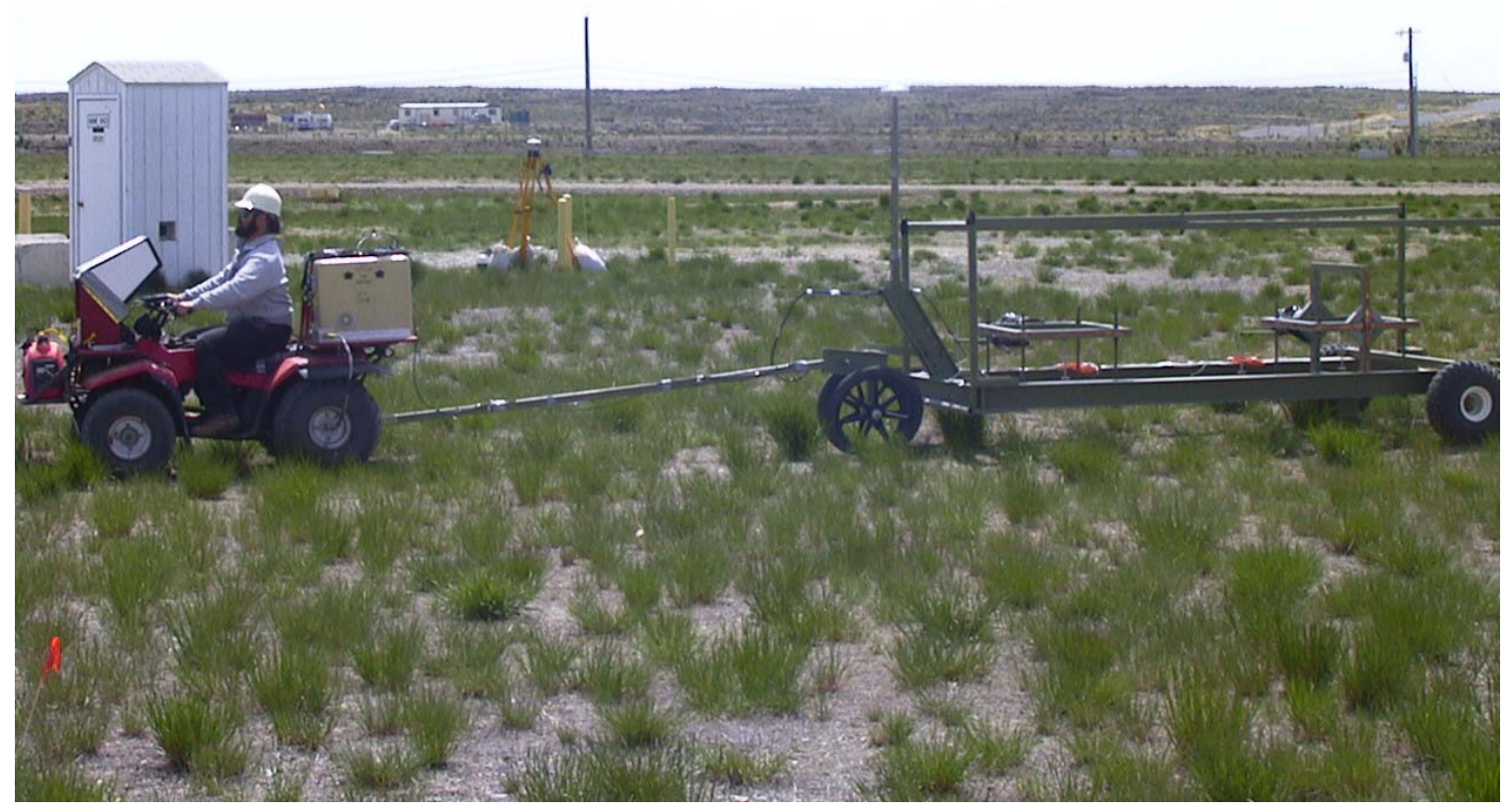

Figure 4 Photograph of the VETEM ATV-towed platform and GPS base station.

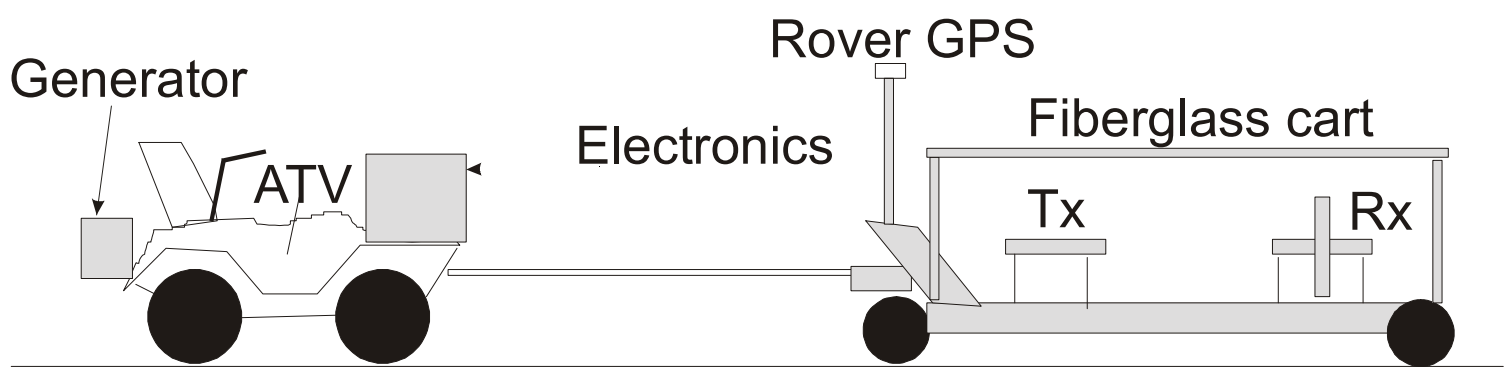

Figure 5 Schematic diagram of the VETEM ATV-towed platform. 


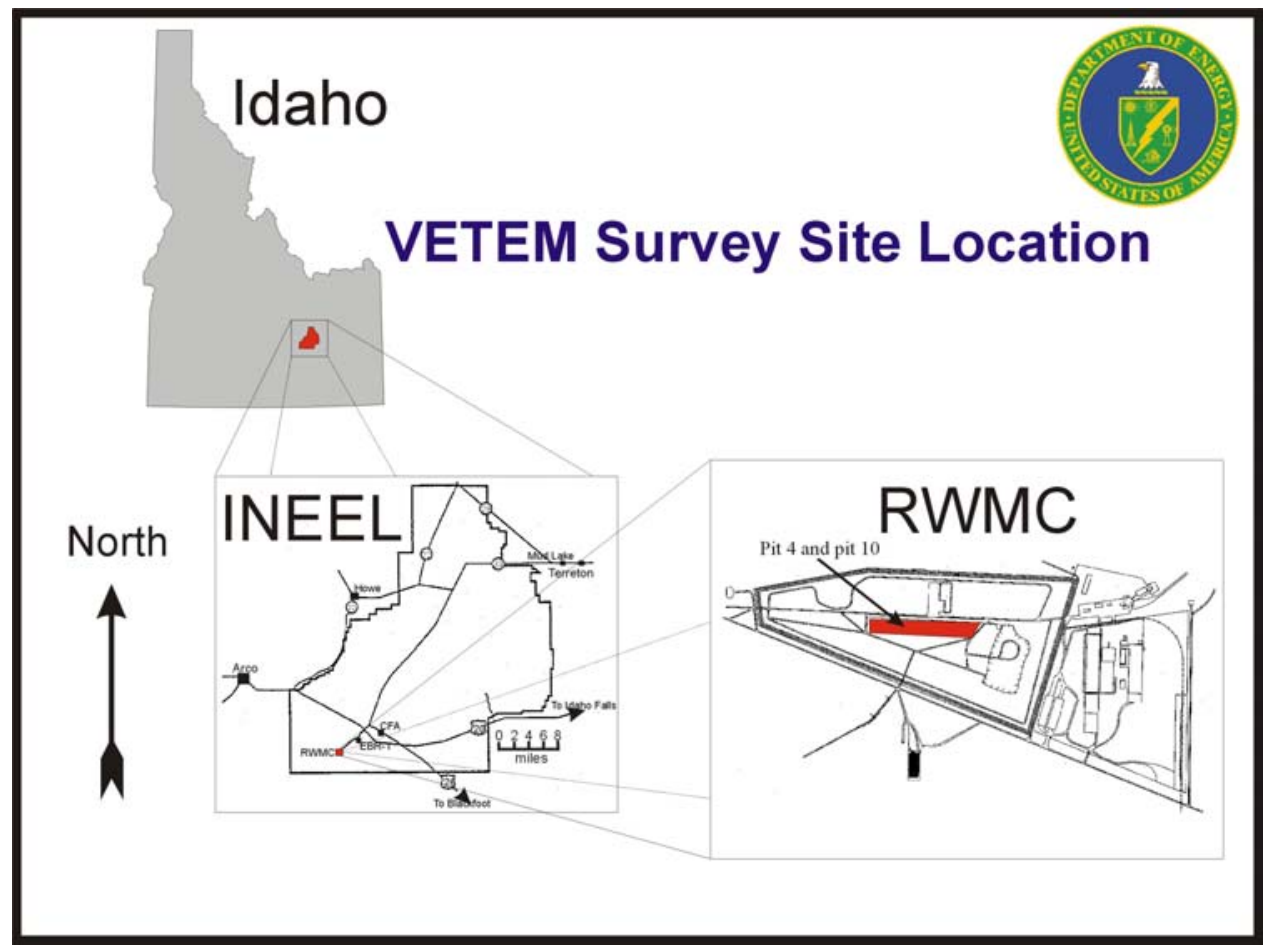

Figure 6 Site location map.

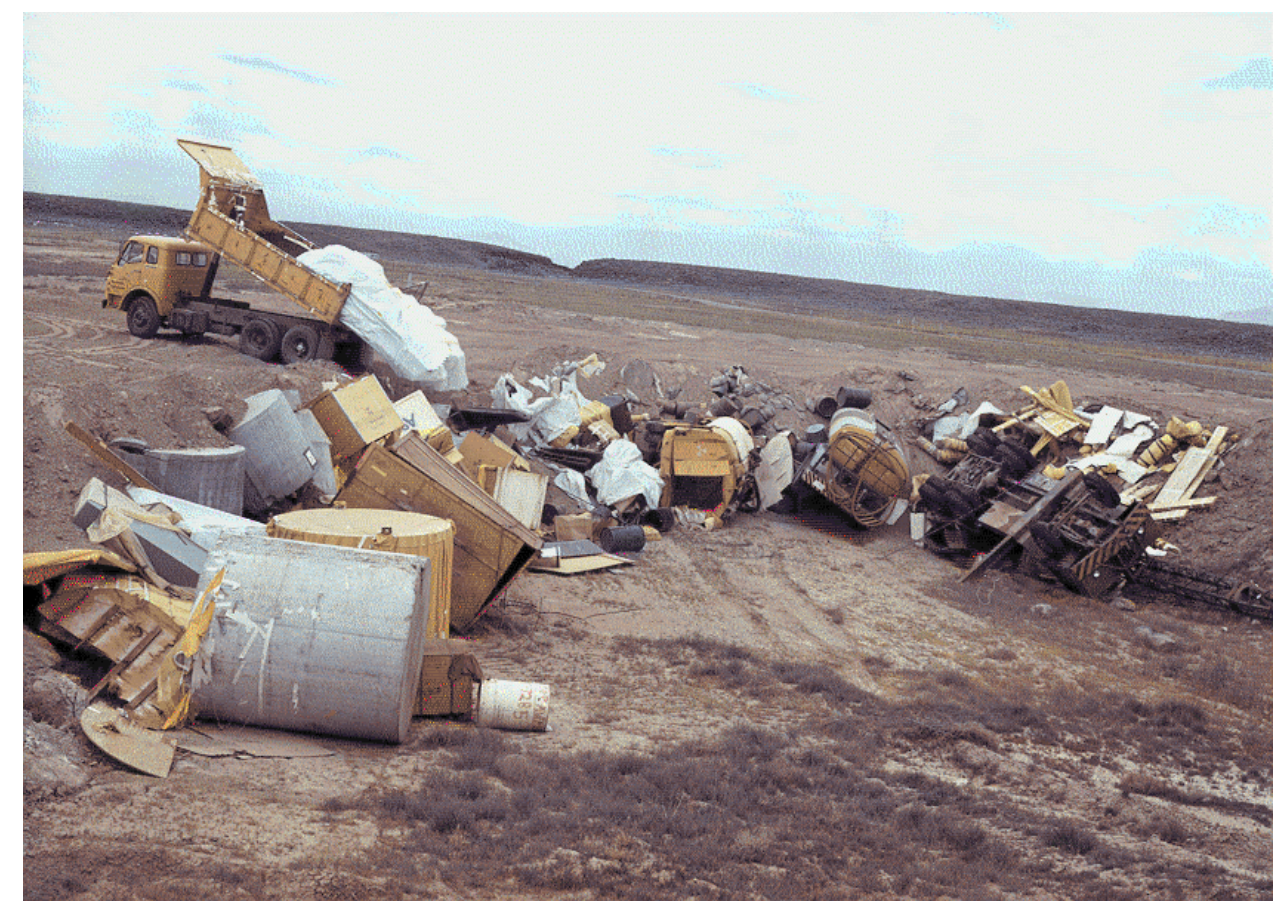

Figure 7 Waste disposal at the SDA (RWMC, circa 1973). 


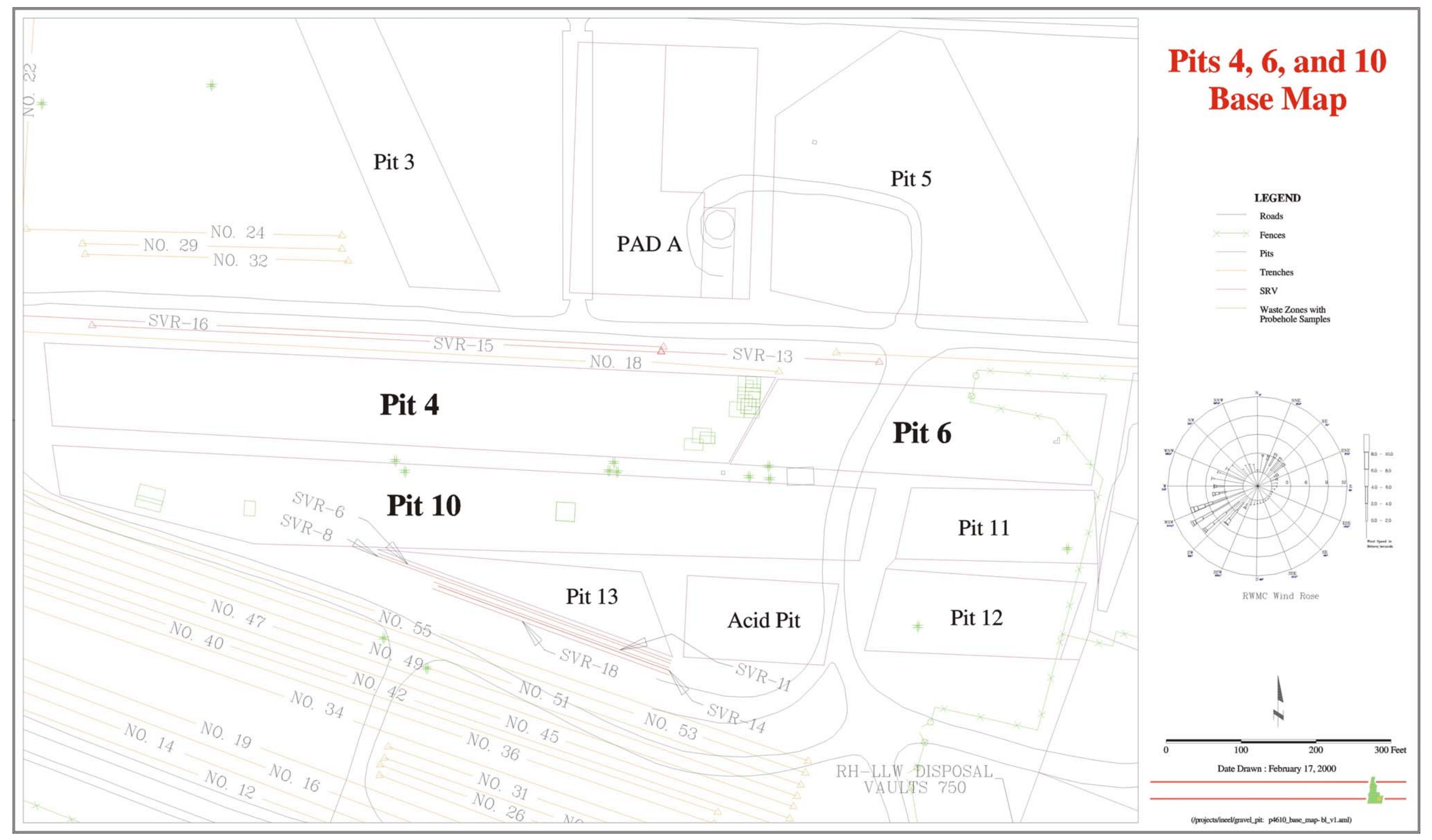

Figure 8 RWMC, SDA, Pit 4, 6, 10 base map. 


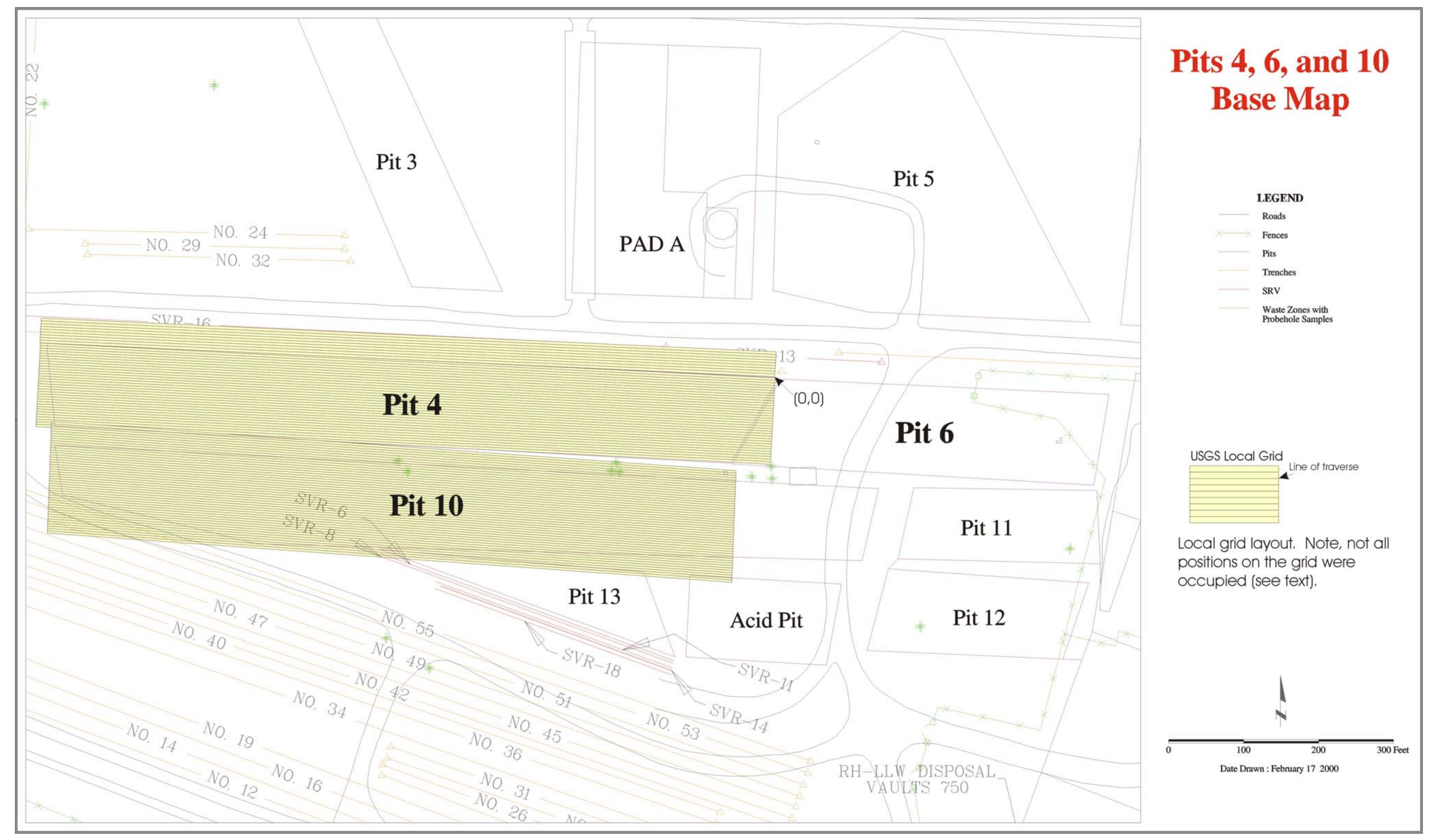

Figure 9 Map showing the layout of the local grid. 


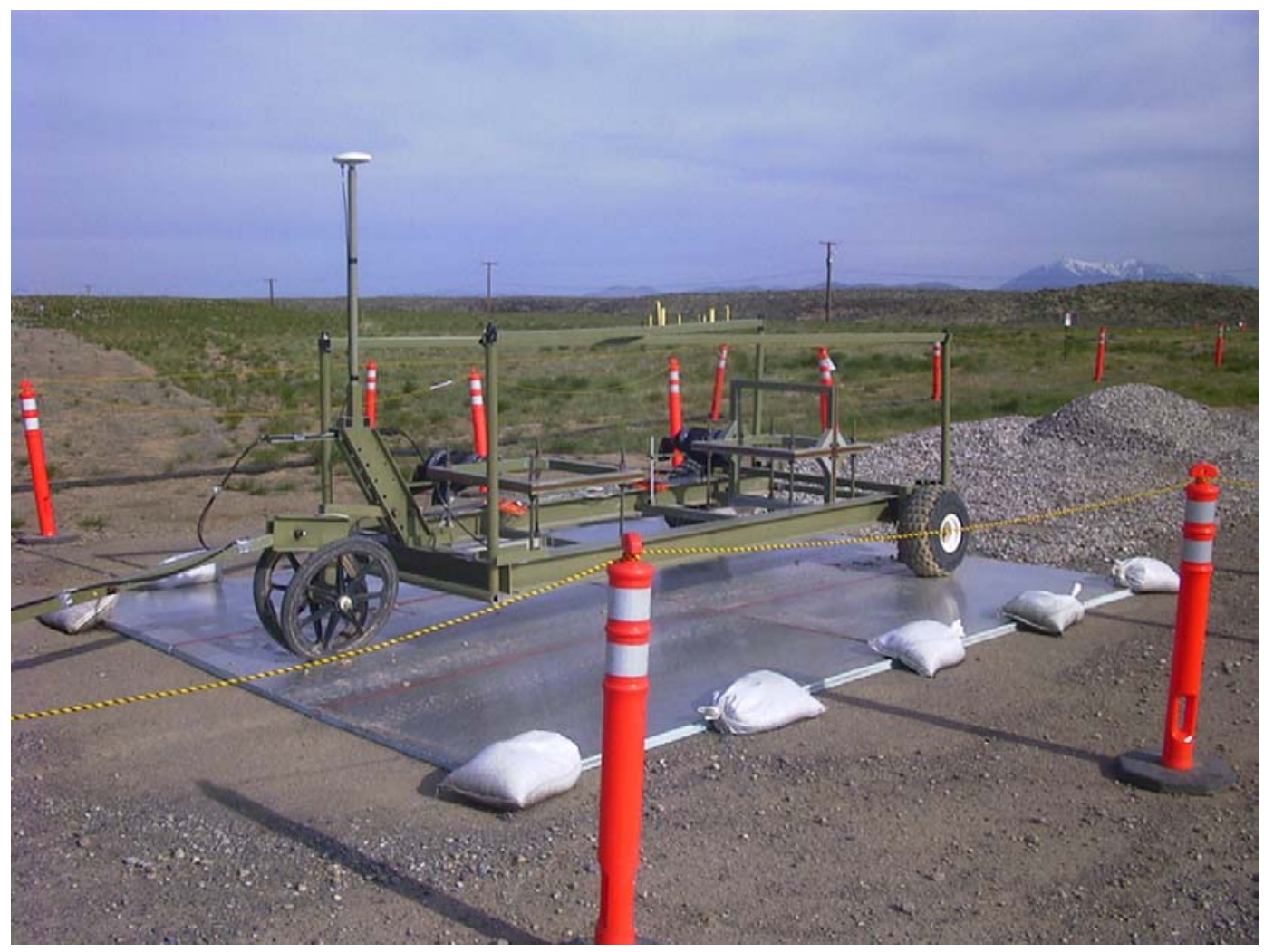

Figure 10 Photograph of the VETEM cart and antennas on the calibration pad.

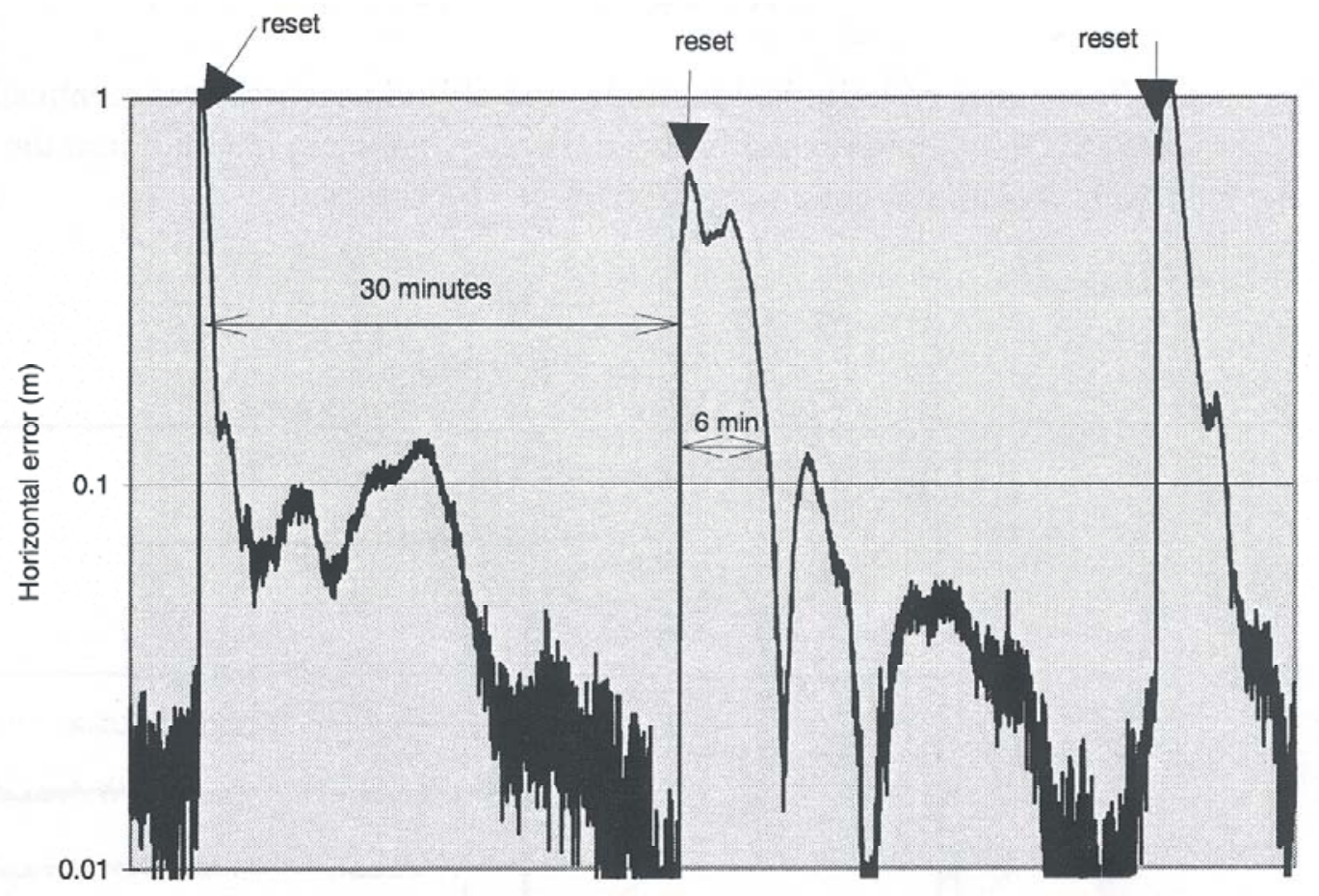

Figure 11 Plot showing convergence of float solution (Ashtech, 1998).

Final Report February, 2003

VETEM Survey of Pit 4 and Pit 10

RWMC, INEEL
United States Geological Survey

Crustal Imaging and Characterization Team

Page 23 


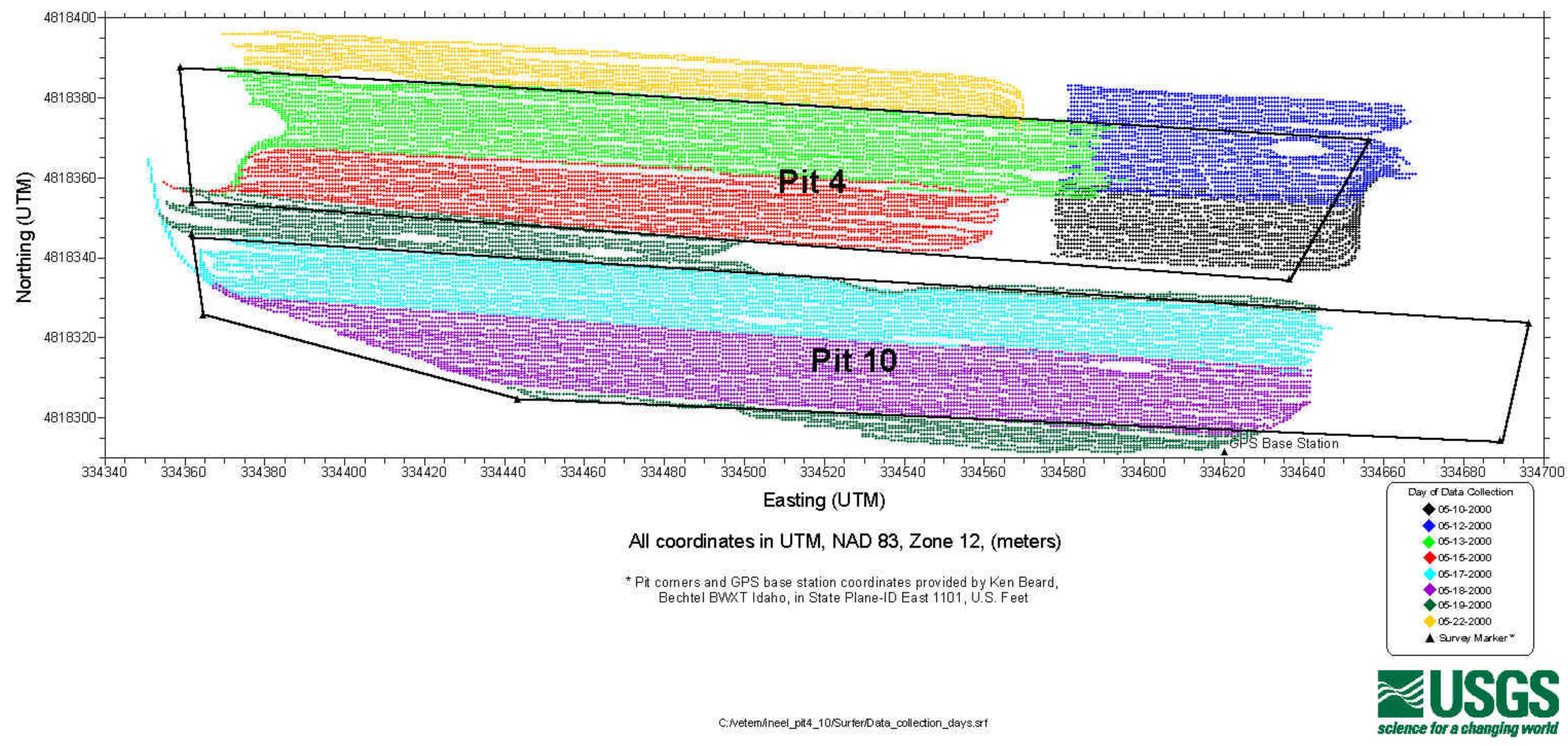

Figure 12 Daily data collection areas. 


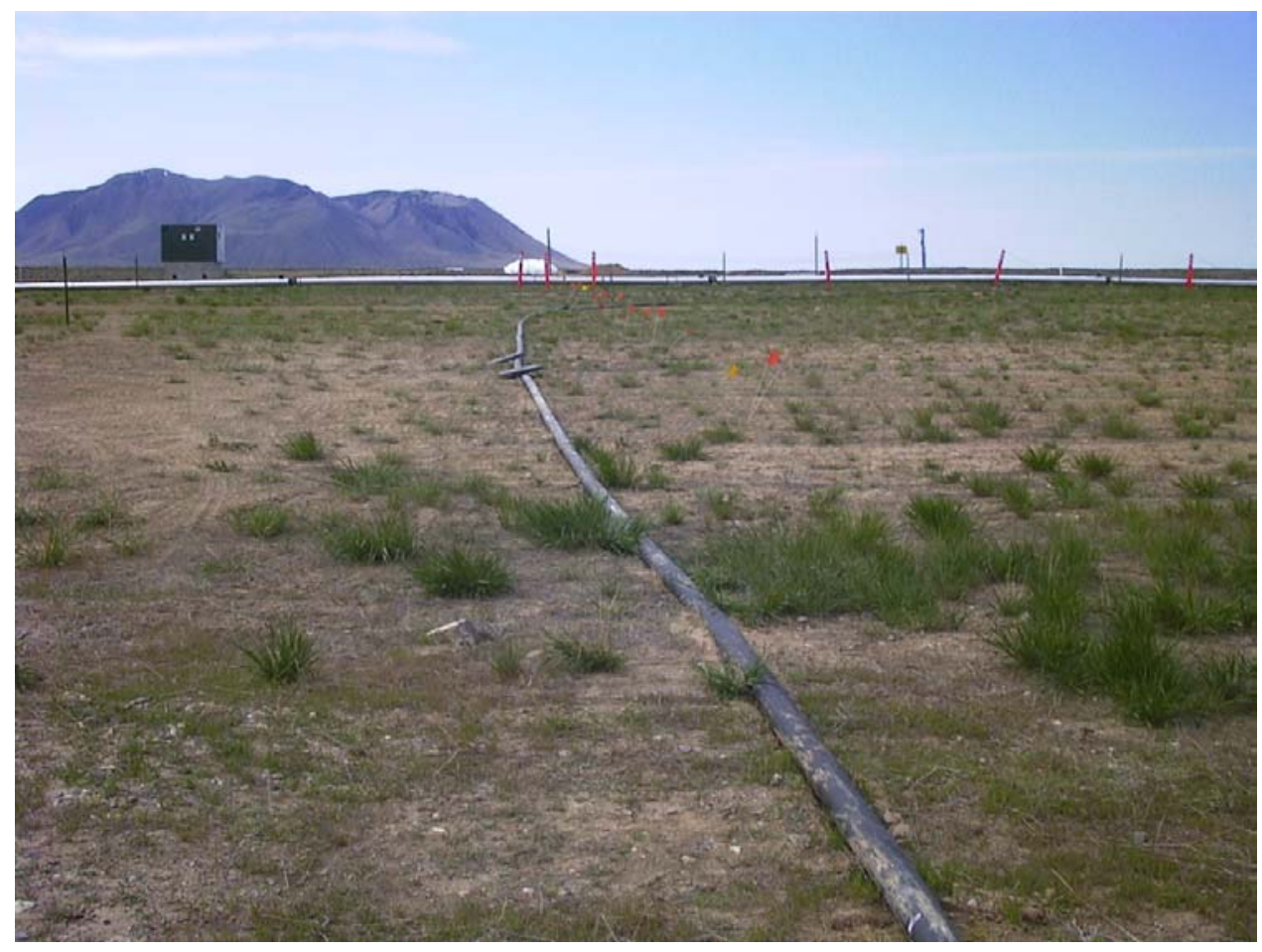

Figure 13 Photograph of power cable on the ground surface.

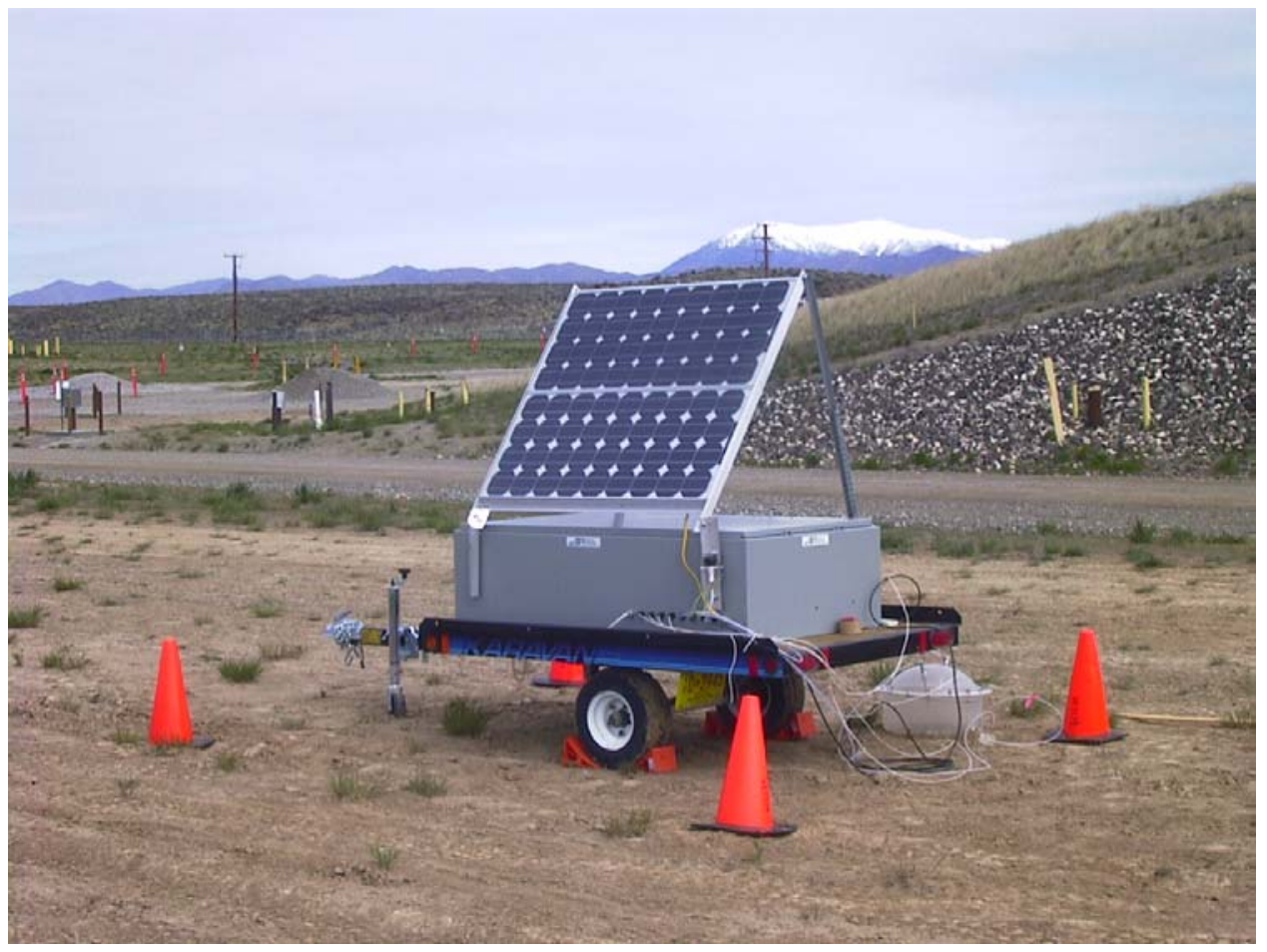

Figure 14 Photograph of equipment parked on the east end of Pit 4.

Final Report February, 2003

VETEM Survey of Pit 4 and Pit 10

RWMC, INEEL
United States Geological Survey

Crustal Imaging and Characterization Team

Page 25 


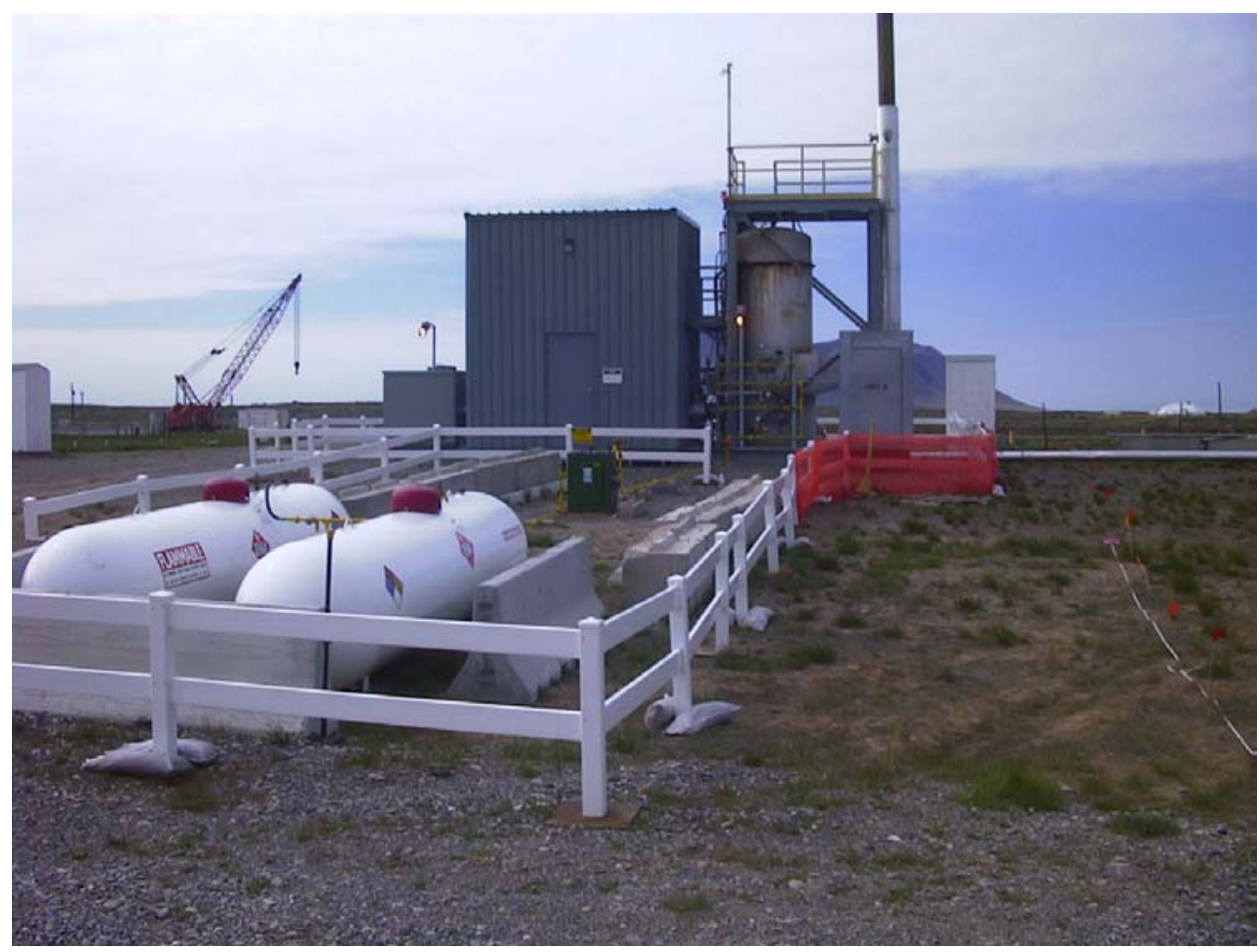

Figure 15 Photograph of site obstacles.

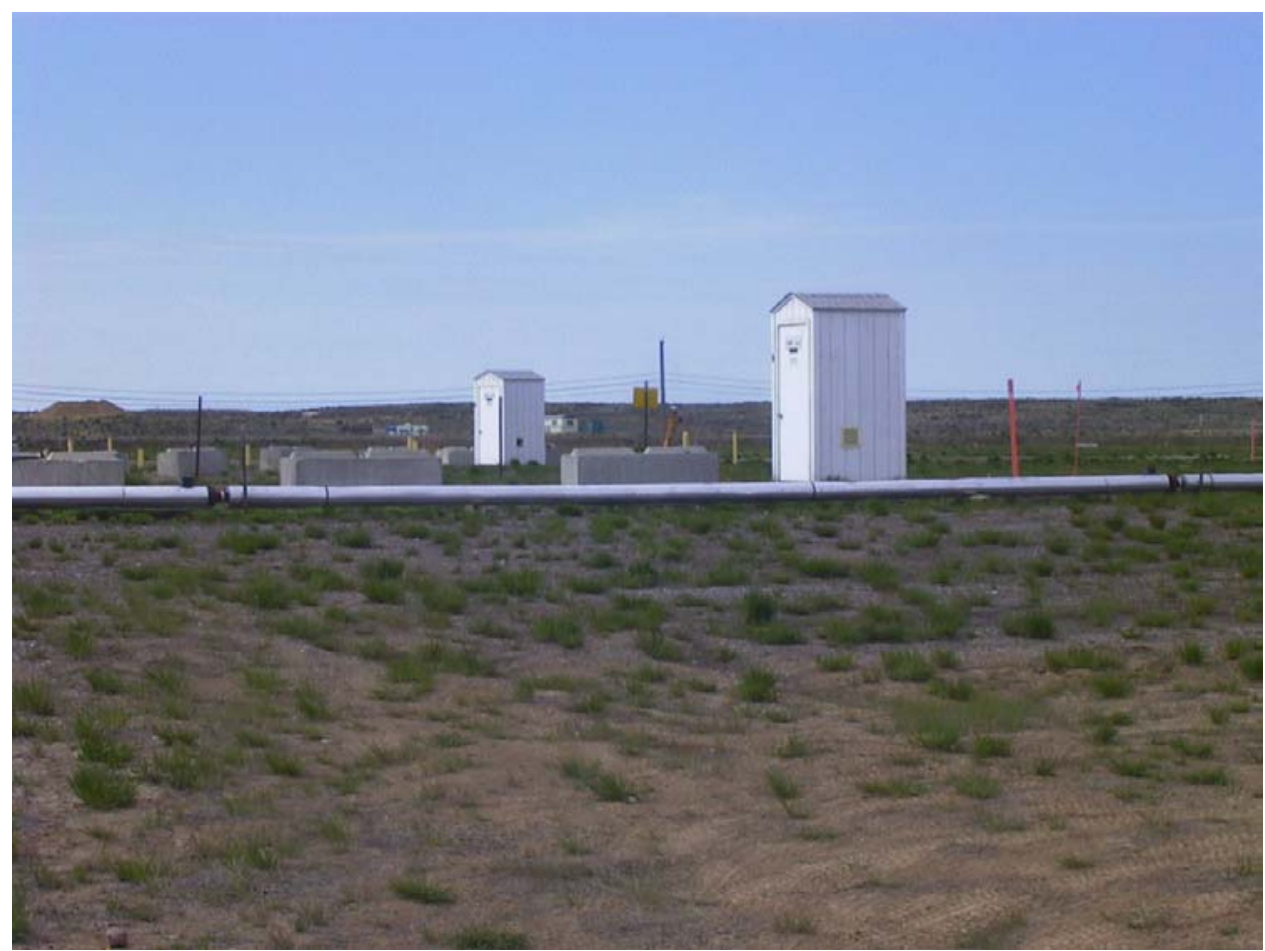

Figure 16 Photograph of site obstacles. 


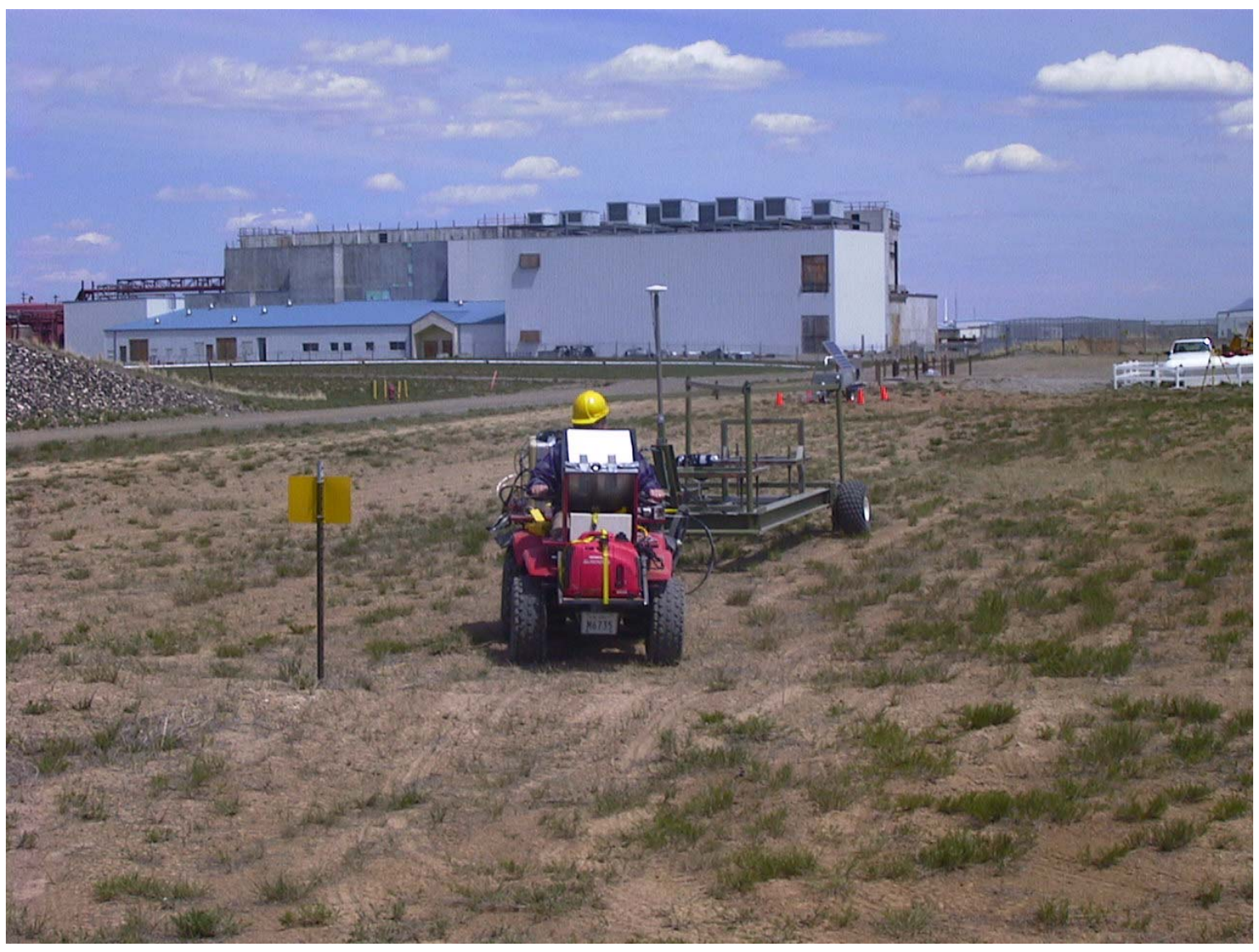

Figure 17 Photograph of data collection along traverses. 


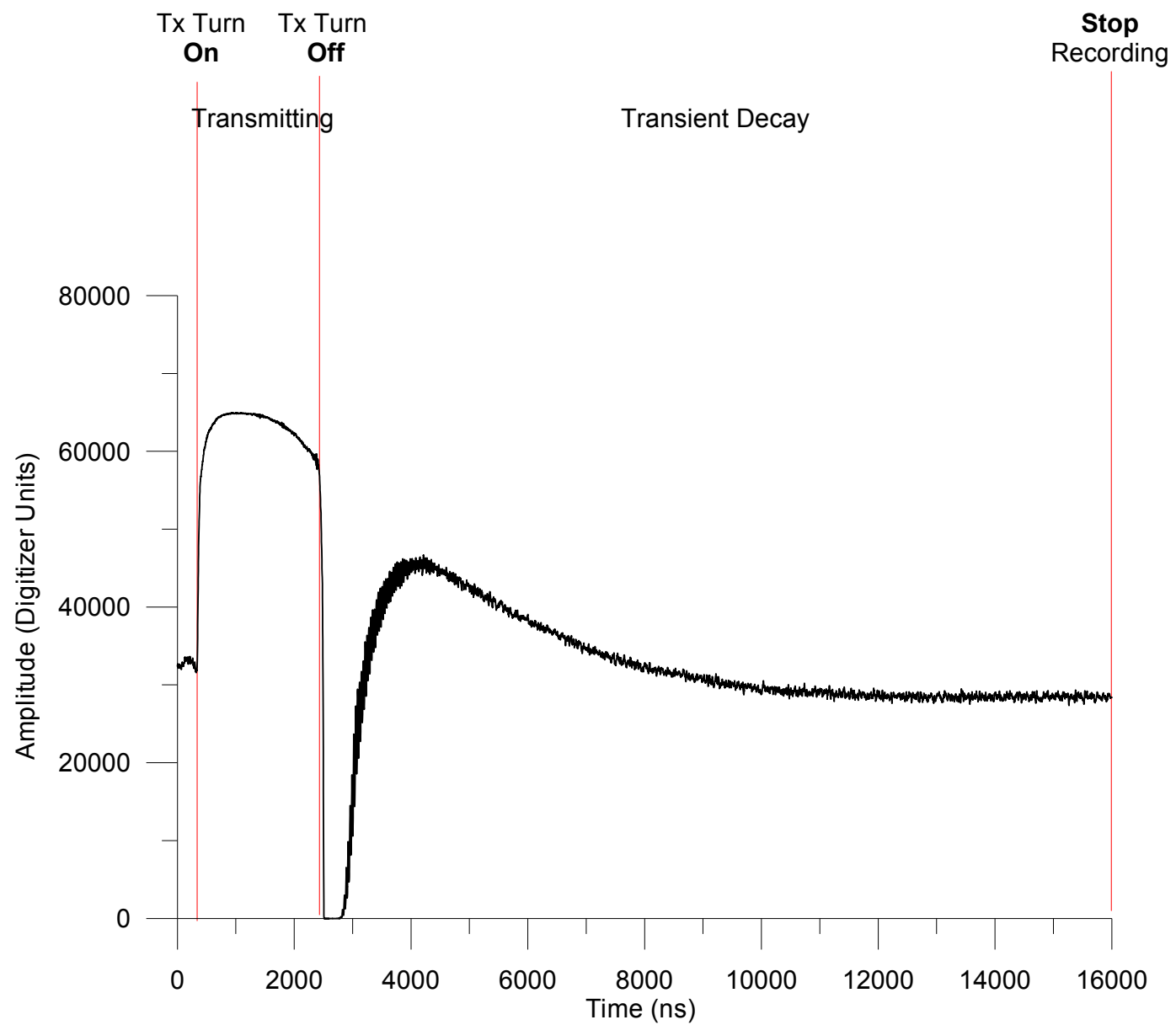

Figure 18 Averaged received time series from the VETEM system.

Final Report February, 2003

VETEM Survey of Pit 4 and Pit 10

RWMC, INEEL
United States Geological Survey Crustal Imaging and Characterization Team 


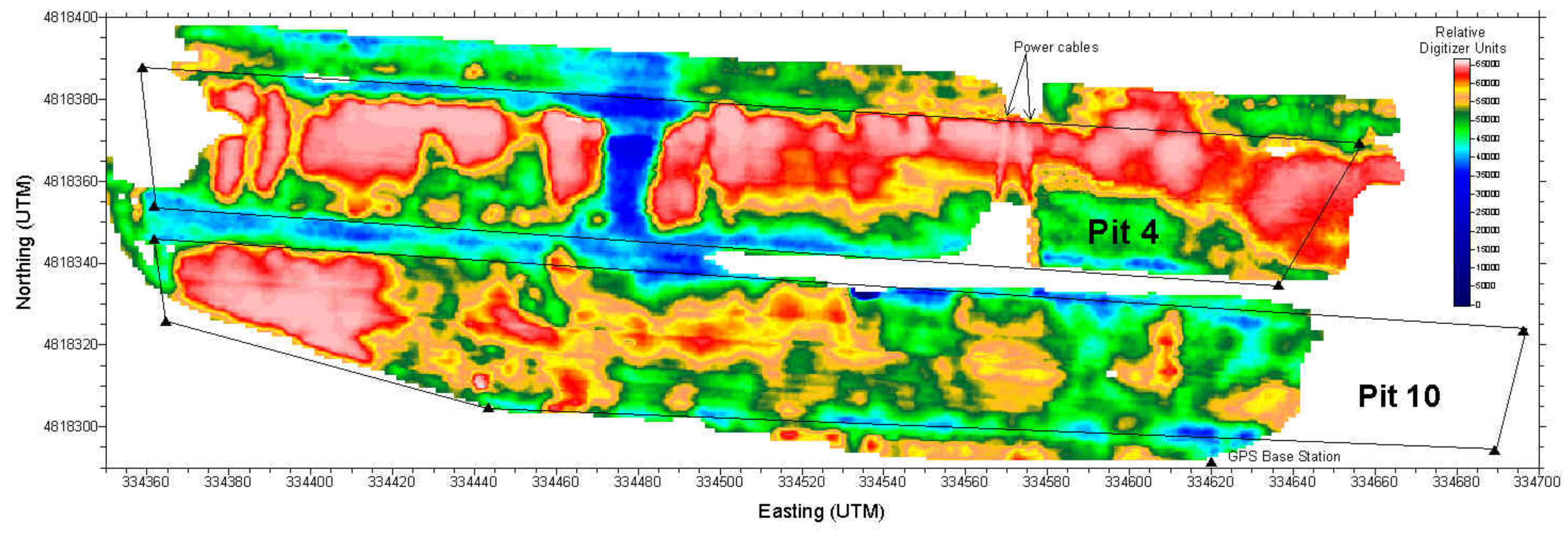

Perpendicular 30 in. square loops, @1500 (ns)

Figure 19 Time slice at 1500 ns of Pit 4 and Pit 10 


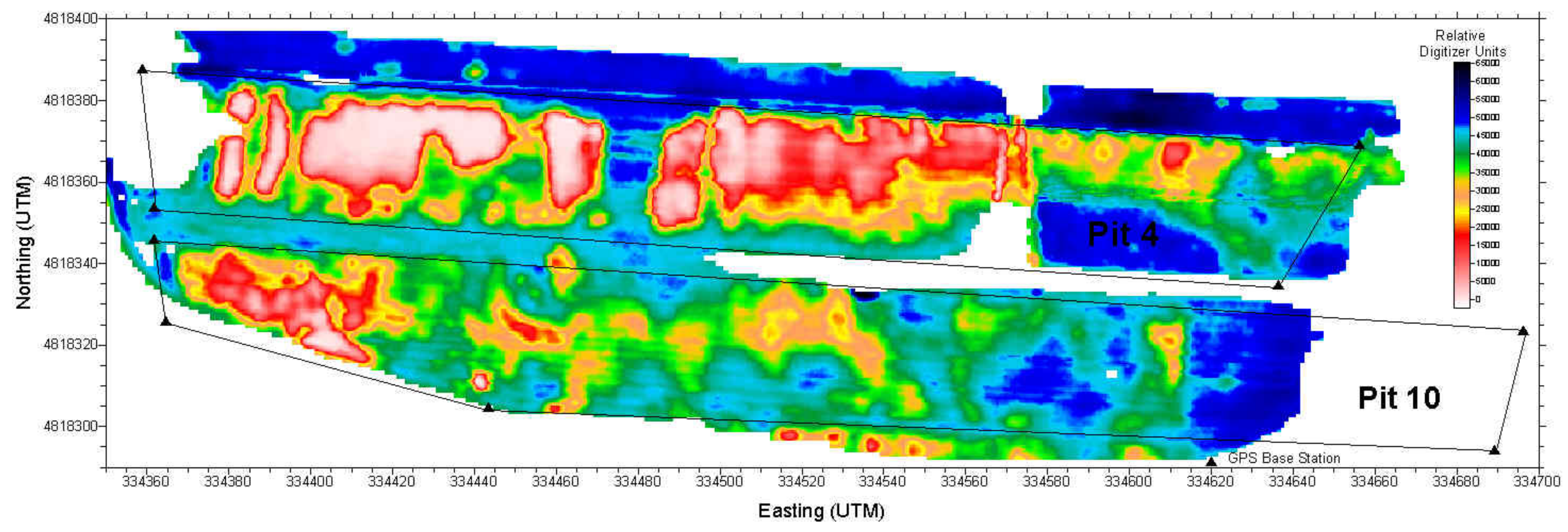

Perpendicular 30 in. square loops, @ 3800 (ns)

Figure 20 Time slice at 3800 ns of Pit 4 and Pit 10 


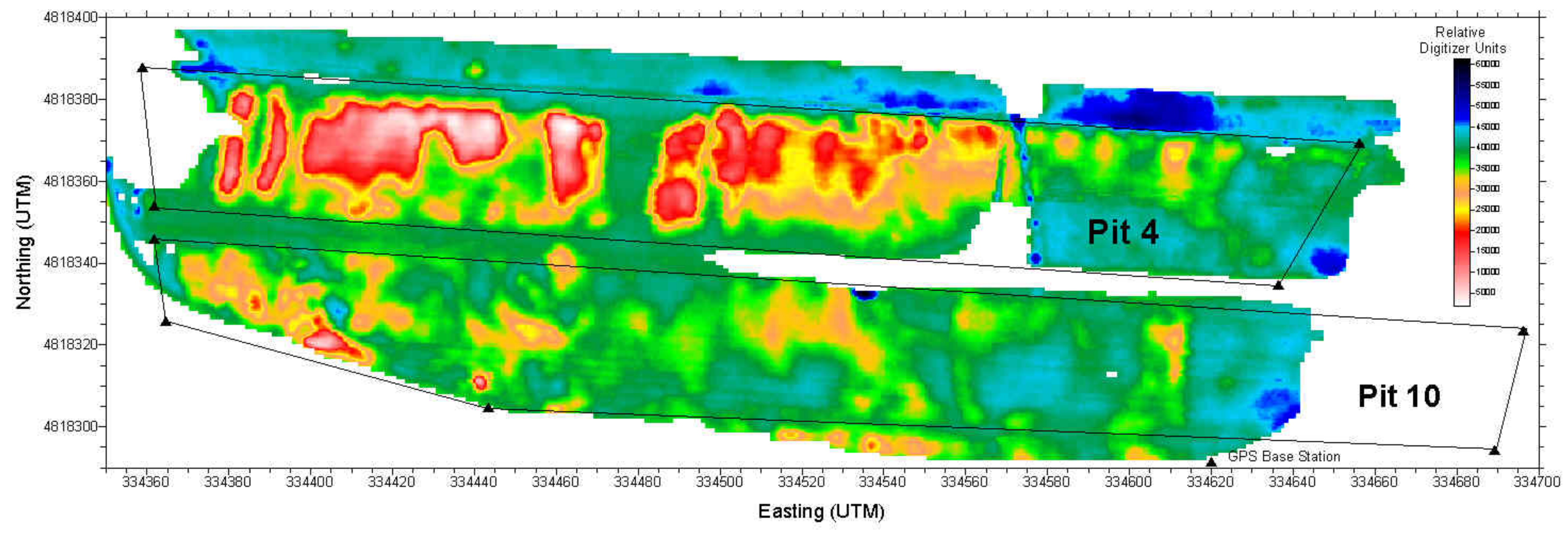

Perpendicular 30 in. square loops, @ 5000 (ns)

Figure 21 Time slice at 5000 ns of Pit 4 and Pit 10 


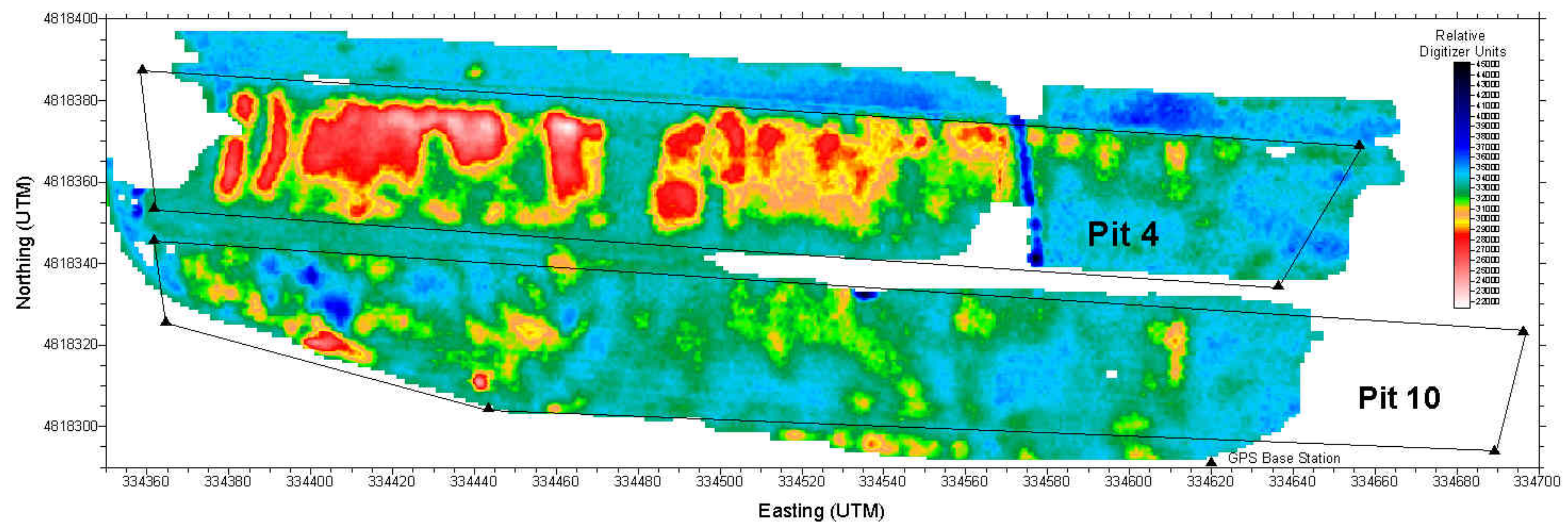

Perpendicular 30 in. square loops, @ 7000 (ns)

Figure 22 Time slice at 7000 ns of Pit 4 and Pit 10 

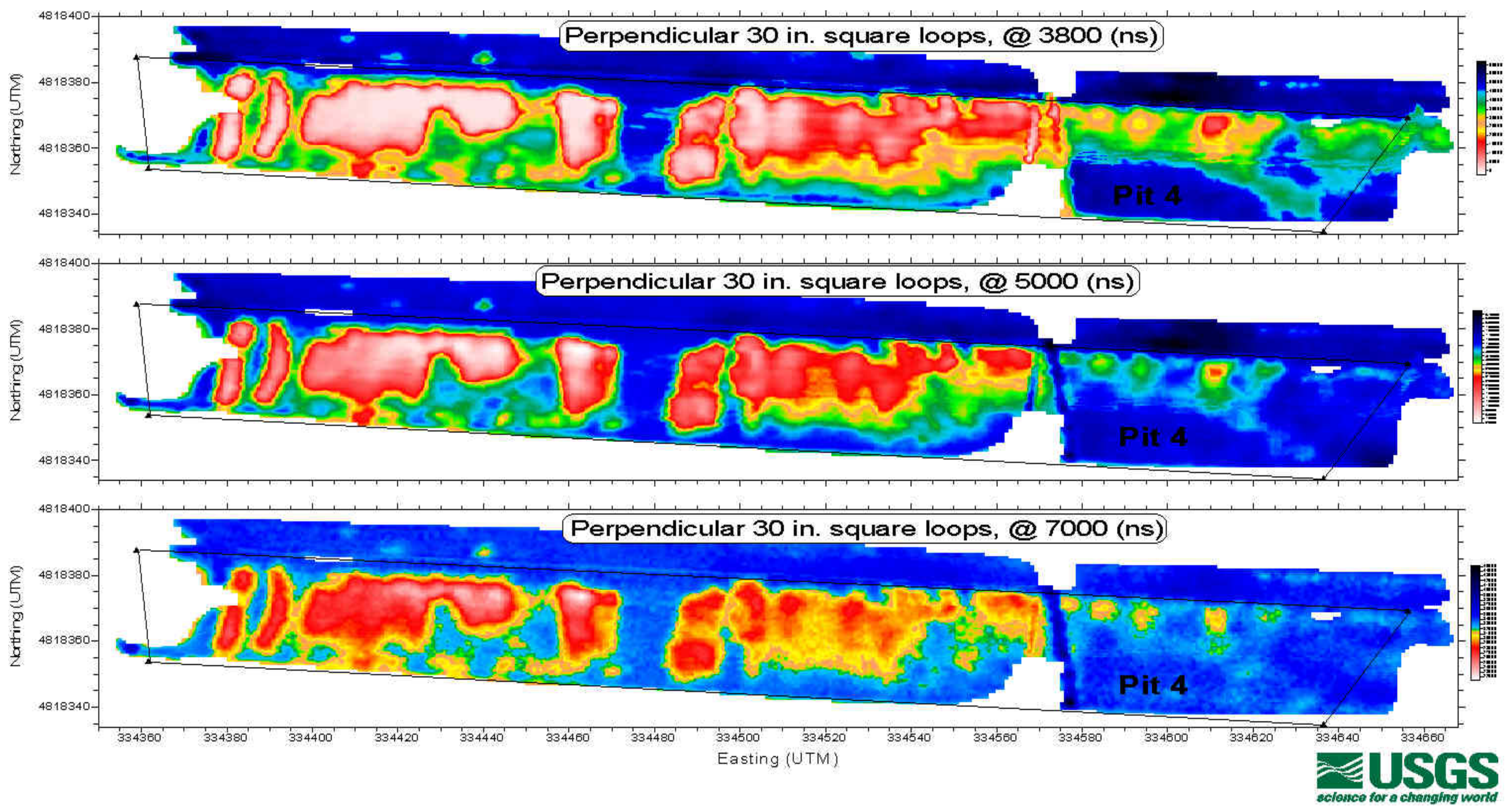

Figure 23 Time slices at 3800, 5000, and 7000 ns of Pit 4. 

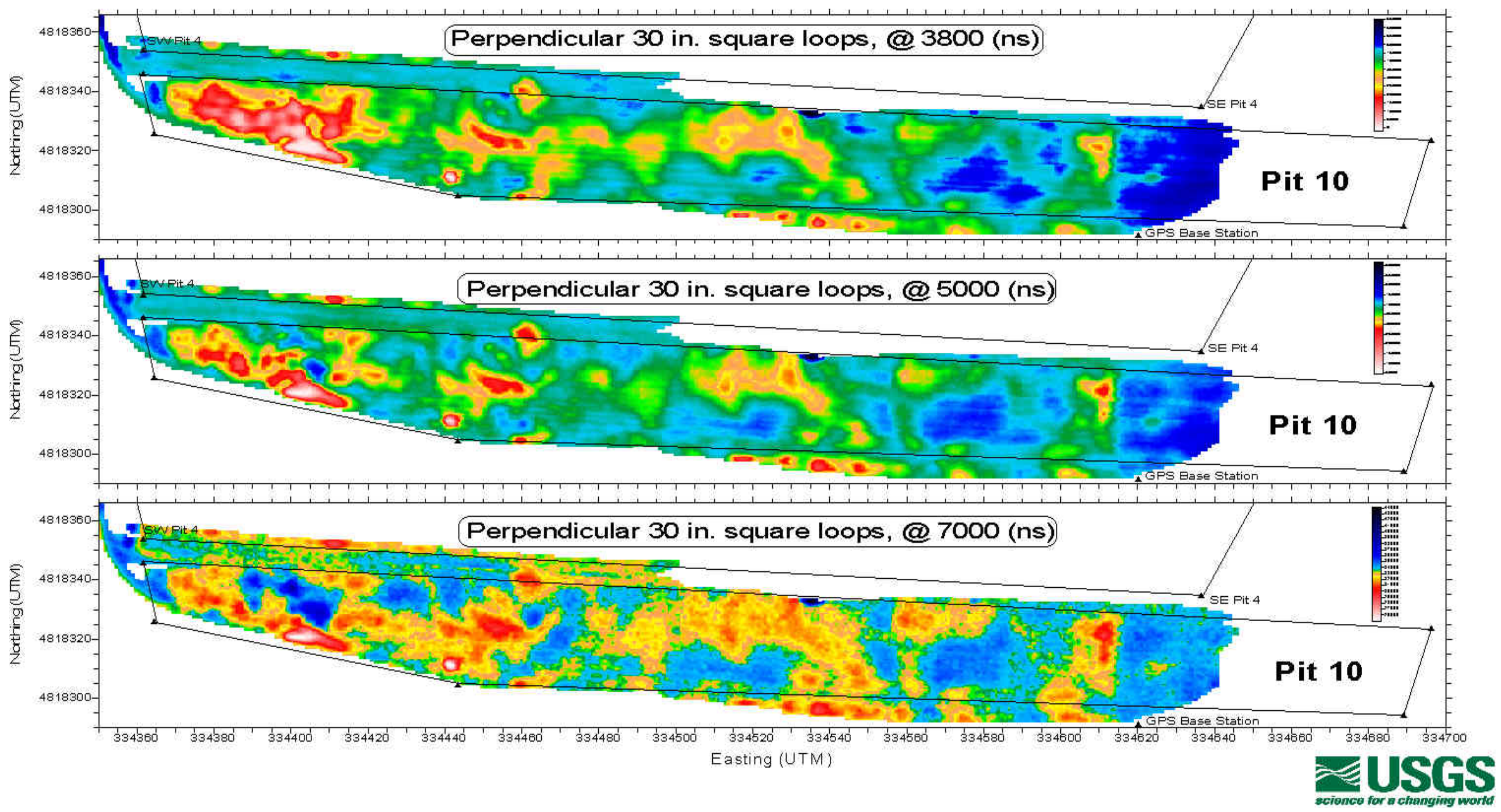

Figure 24 Time slices at 3800, 5000, and 7000 ns of Pit 10. 


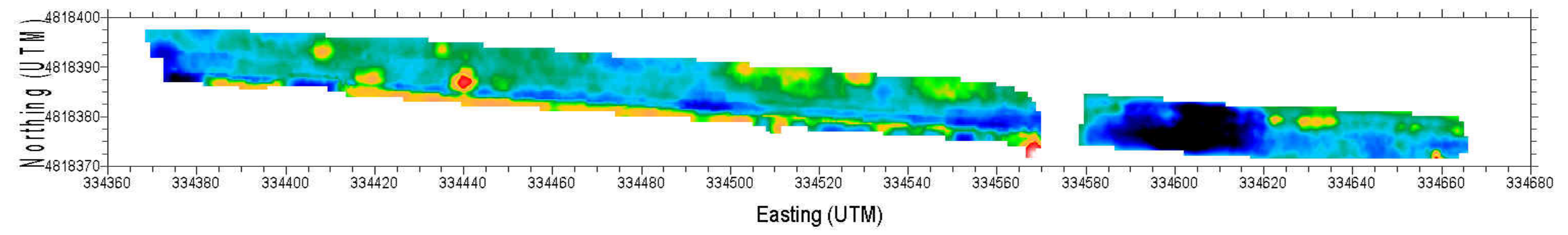

Trench @ 3800 ns

Figure 25 Time slice at $3800 \mathrm{~ns}$ of the trench area north of Pit 4 


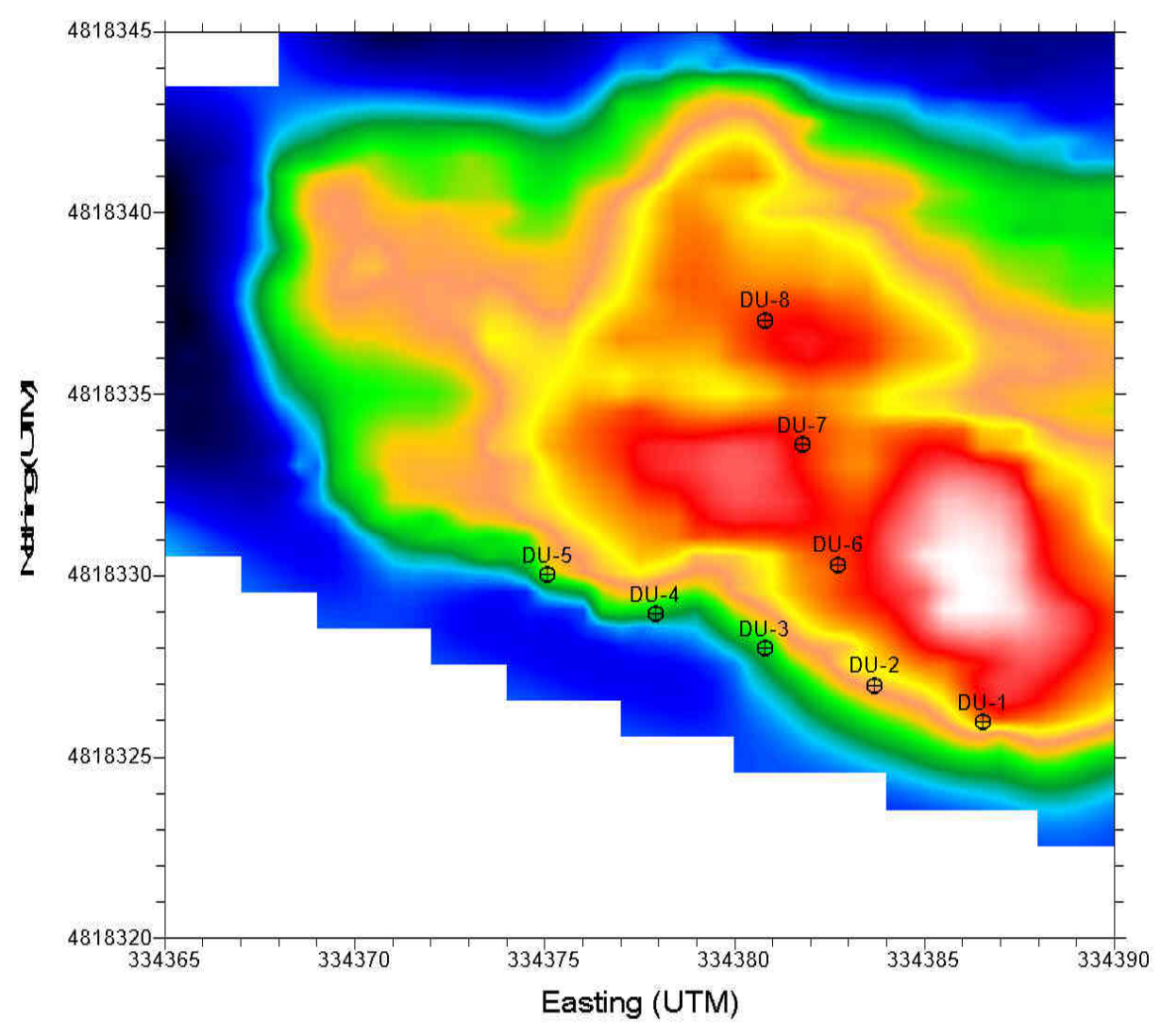

Relative Digitizer Units

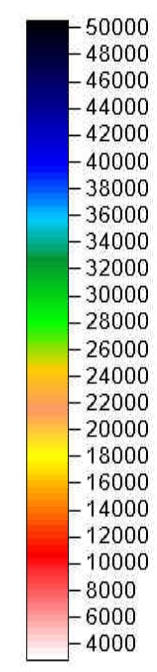

VETEM Perpendicular Antennas @3800 ns

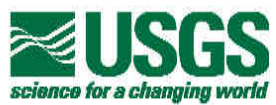

Figure 26 Time slice at $3800 \mathrm{~ns}$ of the depleted uranium focus area. 


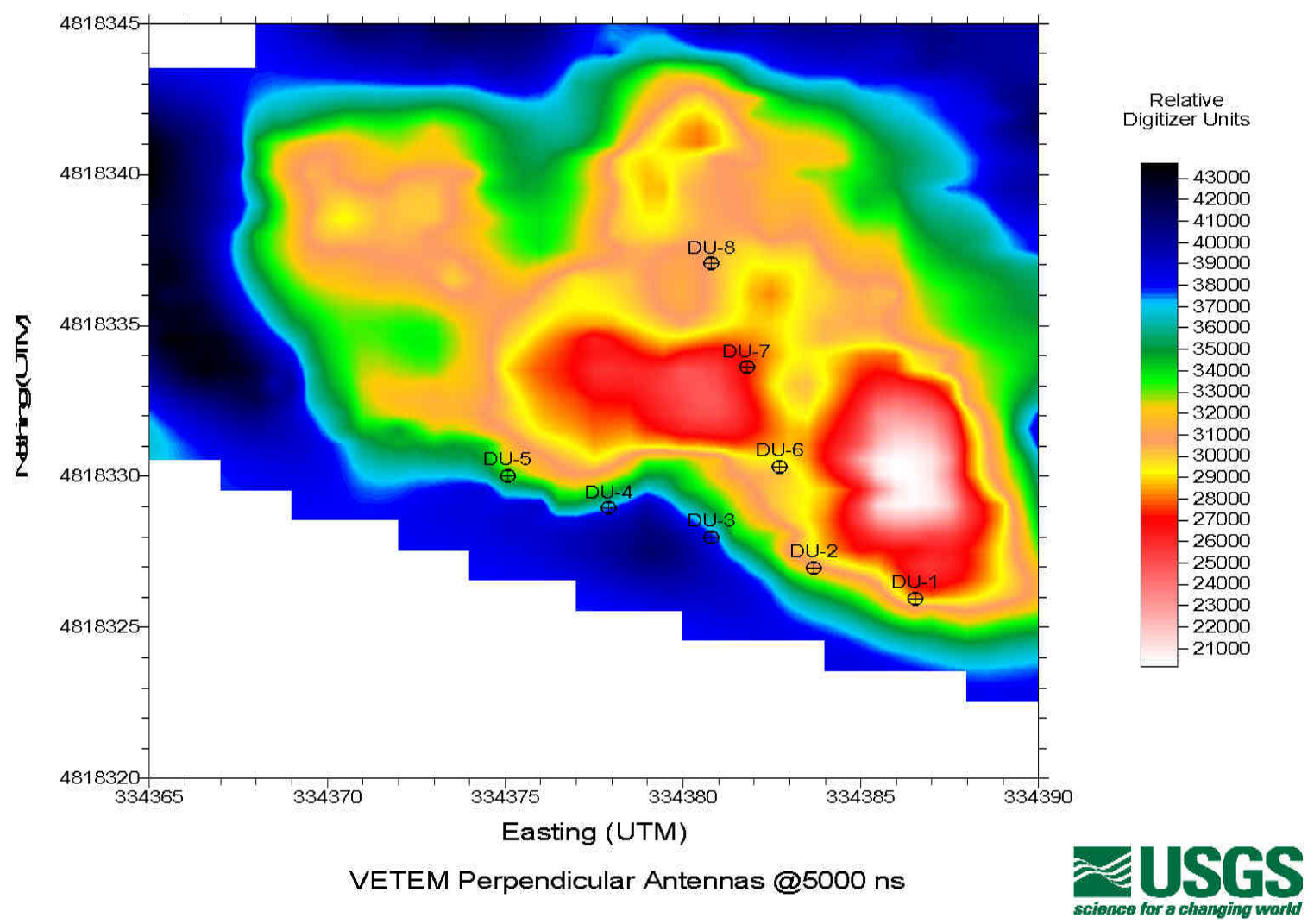

Figure 27 Time slice at $5000 \mathrm{~ns}$ of the depleted uranium focus area. 


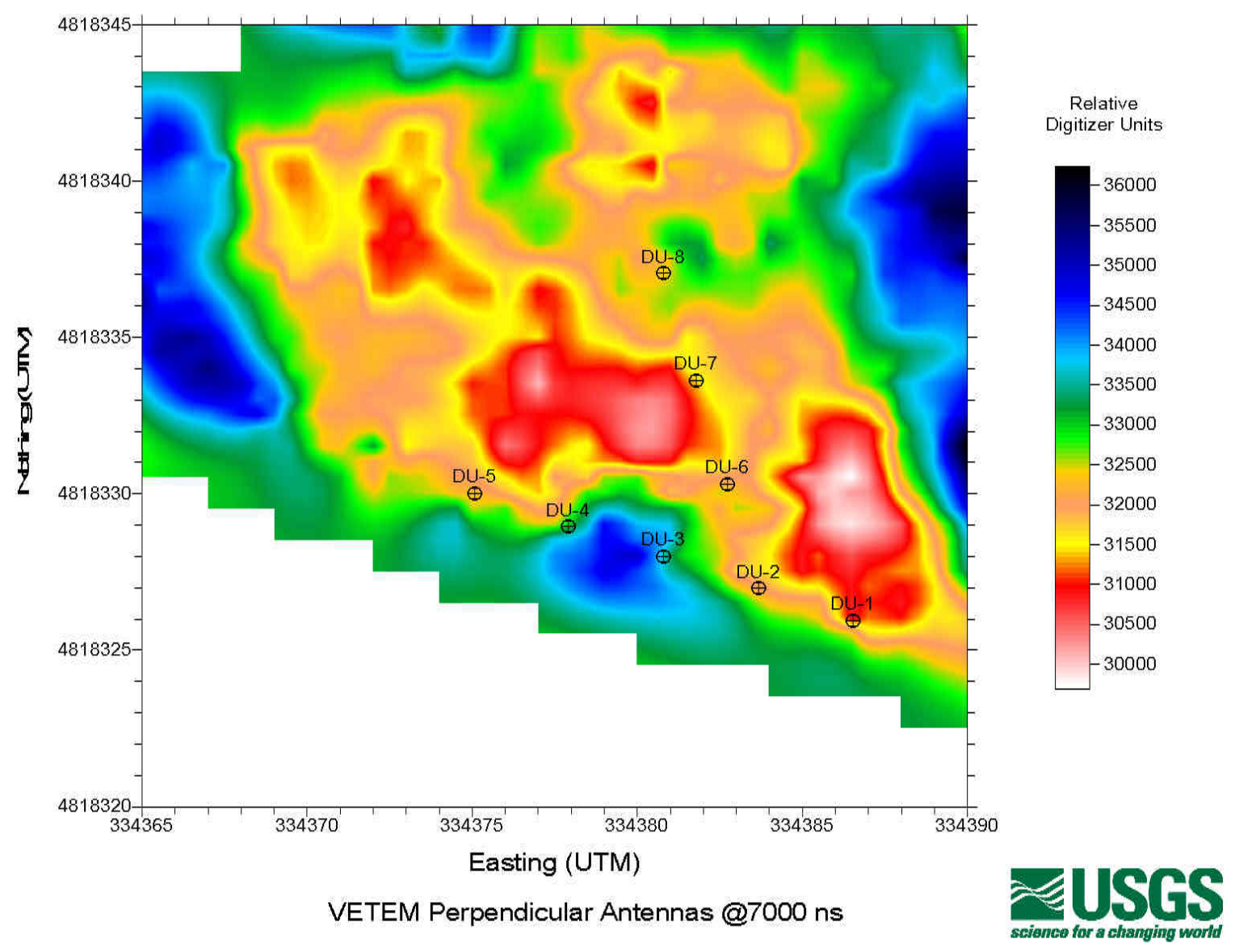

Figure 28 Time slice at $7000 \mathrm{~ns}$ of the depleted uranium focus area. 


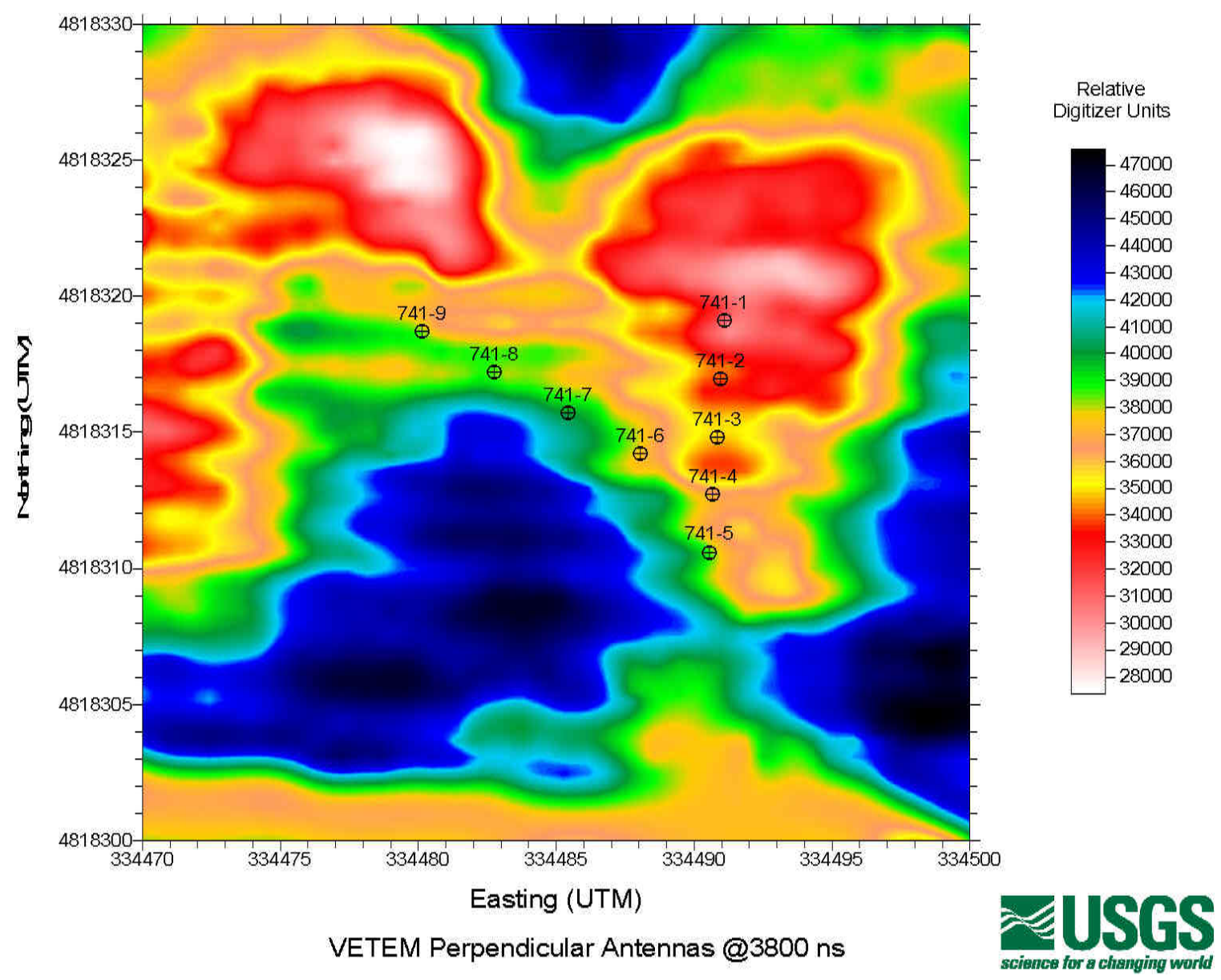

Figure 29 Time slice at $3800 \mathrm{~ns}$ of the $\mathrm{Am} / \mathrm{Np}$ focus area. 


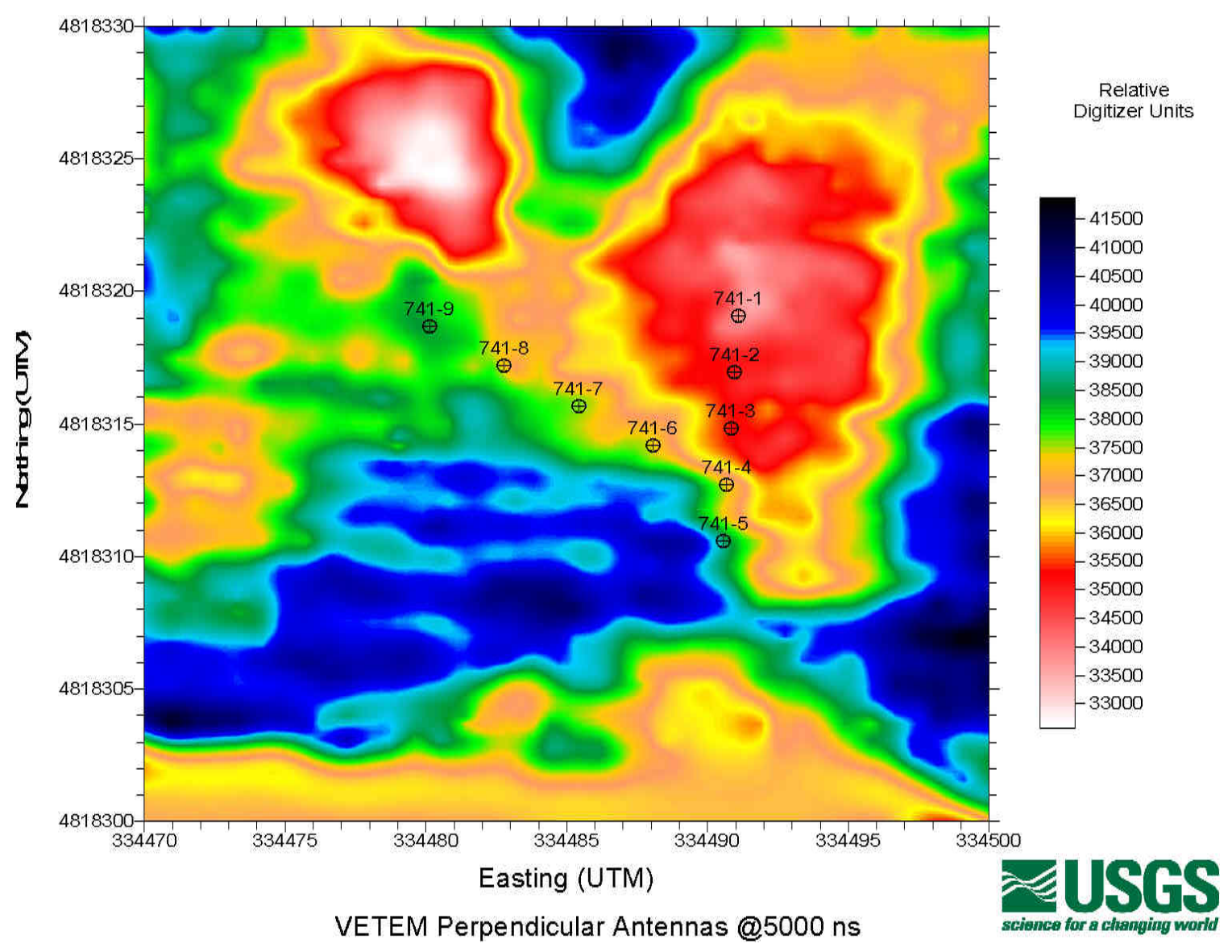

Figure 30 Time slice at $5000 \mathrm{~ns}$ of the $\mathrm{Am} / \mathrm{Np}$ focus area. 


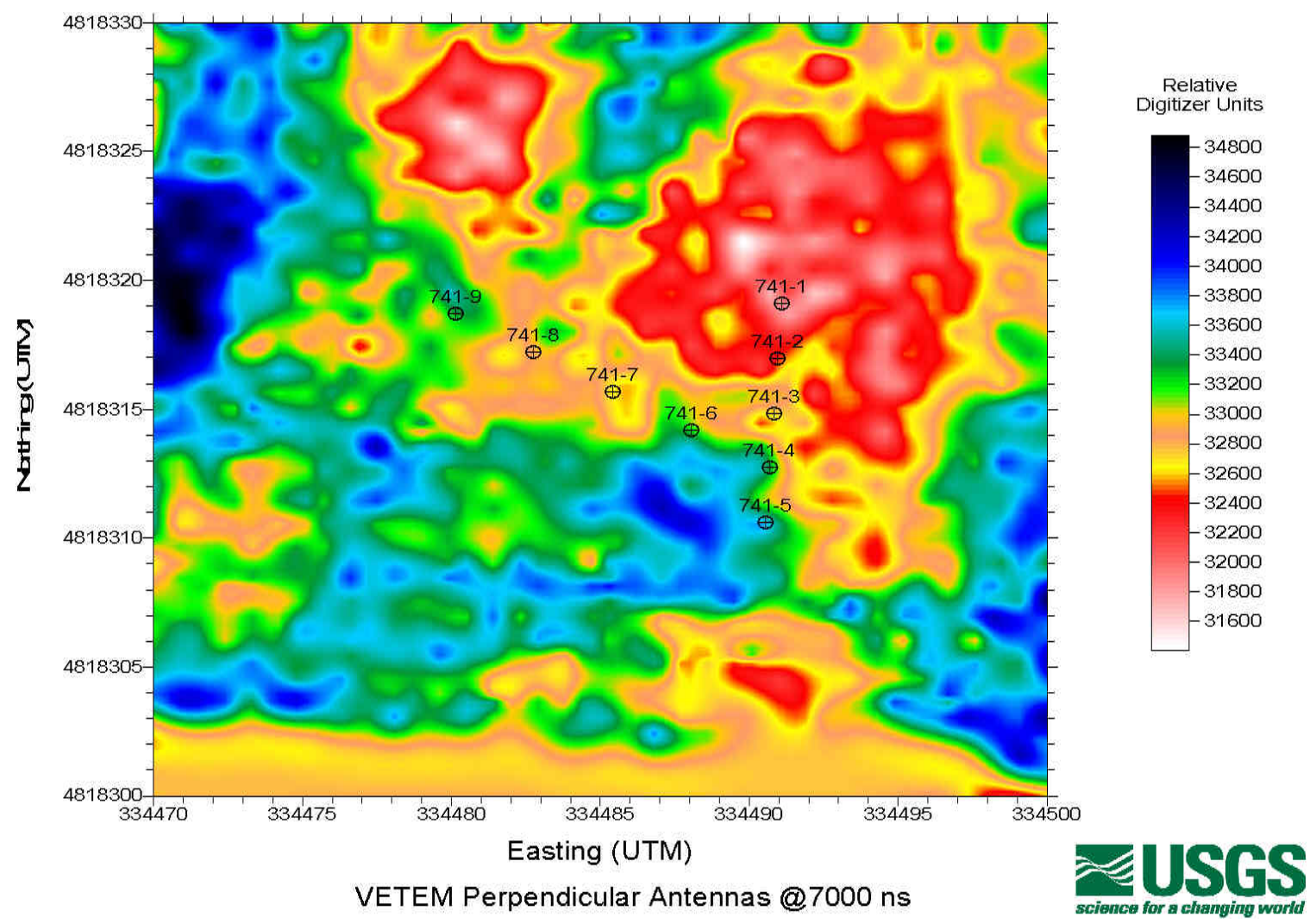

Figure 31 Time slice at $7000 \mathrm{~ns}$ of the Am/ Np focus area. 


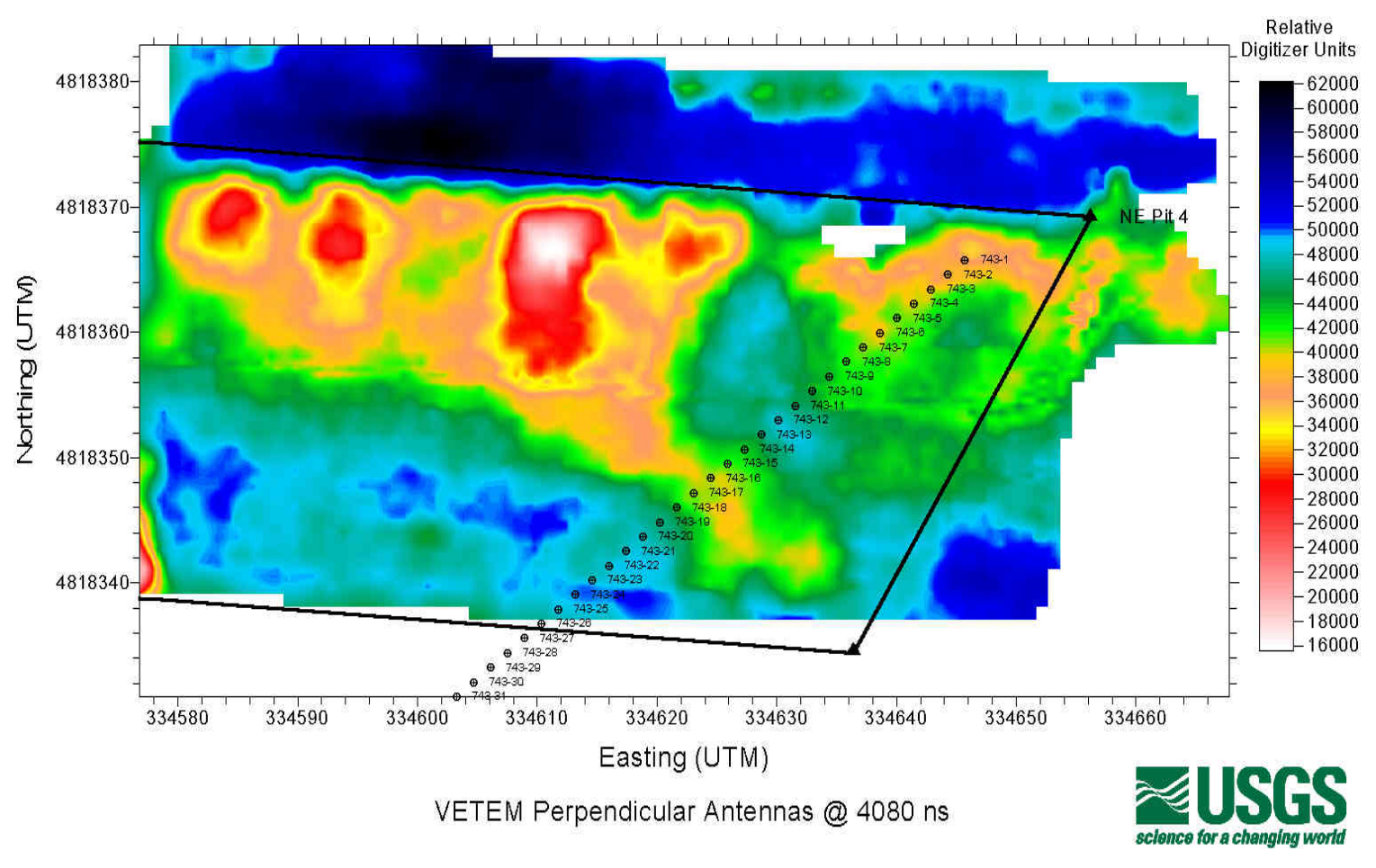

Figure 32 Time slice at 4080ns of the organic sludge focus area. 


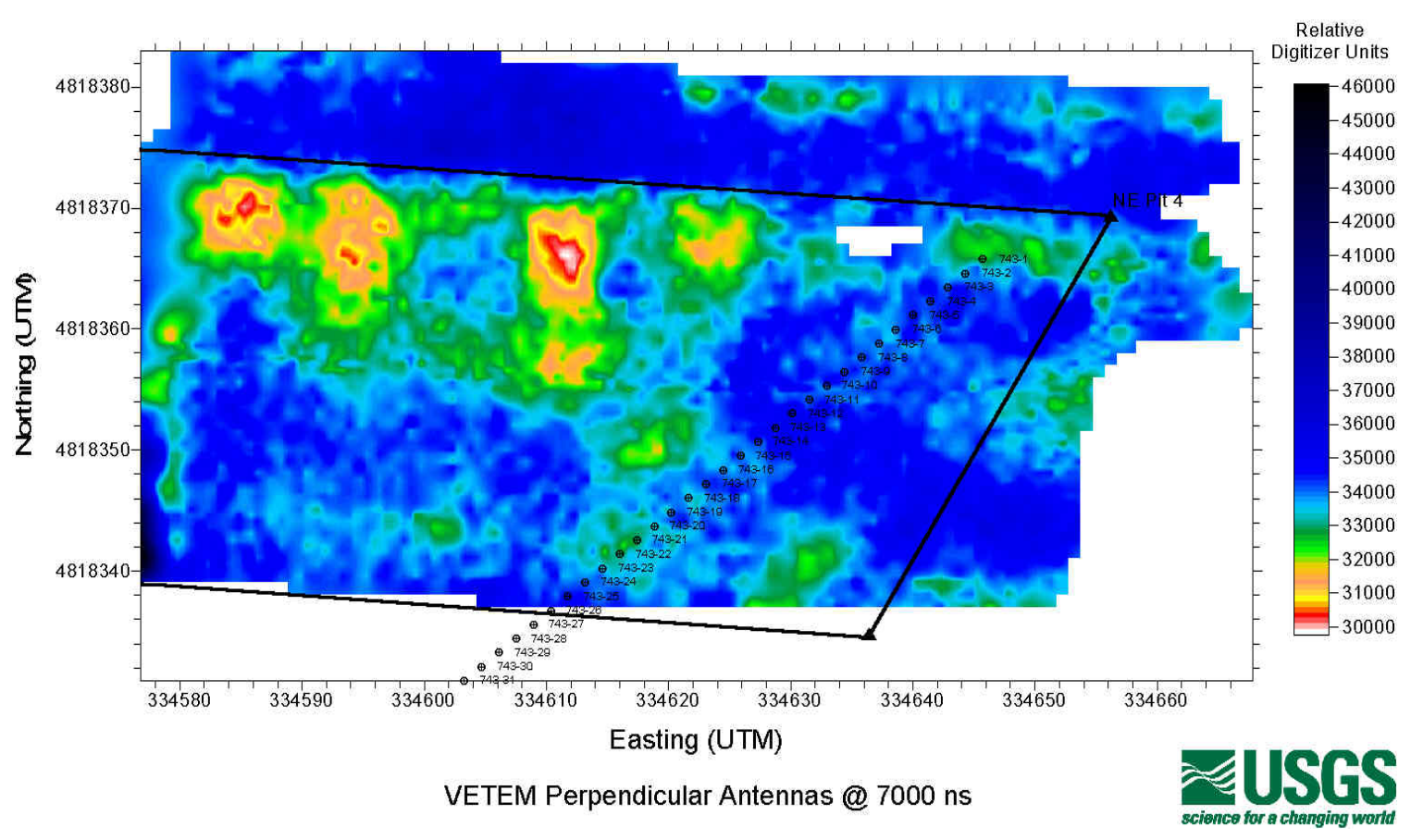

Figure 33 Time slice at 7000ns of the organic sludge focus area. 